\title{
Development of Microstructure and Crystallographic Texture in a Double-Sided Friction Stir Welded Microalloyed Steel
}

S. Rahimi ${ }^{\text {a, }}$, B. P. Wynne ${ }^{\text {b }}$, T. N. Baker ${ }^{c}$

${ }^{a}$ Advanced Forming Research Centre (AFRC), University of Strathclyde, 85 Inchinnan Drive, Inchinnan, Renfrew, PA4 9LJ

${ }^{\mathrm{b}}$ Department of Materials Science and Engineering, Sir Robert Hadfield Building, Mappin Street, Sheffield, S1 3JD

${ }^{c}$ Department of Mechanical and Aerospace Engineering, University of Strathclyde James Weir Building, 75 Montrose Street, Glasgow, G1 1XJ

\begin{abstract}
The evolution of microstructure and crystallographic texture has been investigated in double-sided friction stir welded microalloyed steel, using electron backscatter diffraction (EBSD). The microstructure analyses show that the centre of stirred zone reached a temperature between $\mathrm{Ac}_{1}-\mathrm{Ac}_{3}$ during $\mathrm{FSW}$, resulting in a dual phase austenitic/ ferritic microstructure. The temperatures in the thermo-mechanically affected zone and the overlapped area between the first and second weld pass did not exceed the $\mathrm{Ac}_{1}$. The shear generated by the rotation probe occurs in austenitic/ferritic phase field where the austenite portion of the microstructure is transformed to a bainitic ferrite, on cooling. Analysis of crystallographic textures with regard to shear flow lines generated by the probe tool, show the dominance of simple shear components across the whole weld. The austenite texture at $\mathrm{Ac}_{1}-\mathrm{Ac}_{3}$ is dominated by the $\mathrm{B}\{1 \overline{1} 2\}<110>$ and $\bar{B}\{\overline{1} 1 \overline{2}\}<\overline{1} \overline{1} 0>$ simple shear texture components, where the bainite phase textures formed on cooling were inherited from the shear textures of the austenite phase with relatively strong variant selection. The ferrite portion of the stirred zone and the ferrites in the thermo-mechanically affected zones and the overlapped area underwent shear deformation with textures dominated by the $\mathrm{D}_{1}\{\overline{1} \overline{1} 2\}<111>$ and $\mathrm{D}_{2}\{11 \overline{2}\}<111>$ simple shear texture components. The formation of ultra-fine equiaxed ferrite with submicron grain size has been observed in the overlapped area between the first and second weld pass. This is due to continuous dynamic strain-induced recrystallisation as a result of simultaneous severe shear deformation and drastic undercooling.
\end{abstract}

Keyword: Friction stir welding, Ultra-fine ferrite, Continuous dynamic strain induced recrystallisation, Microalloyed steel

\section{Introduction}

Friction stir welding (FSW), a solid state welding technique originally developed for joining Al-alloys [12], was invented by The Welding Institute (TWI) in the early 1990's, and is now a mature process for welding $\mathrm{Mg}, \mathrm{Cu}$ and $\mathrm{Ti}$ alloys, and Al-metal matrix composites. It is claimed that the advantages of FSW include rapid joining speeds, elimination of weld cracking and porosity and no need for shielding gas of filler metal. All lead to improved mechanical and metallurgical weld properties, and normally, a lower residual stress than fusion welding [1-5]. The restriction of welding only lower melting temperature alloys such as aluminium, due to the severe conditions encountered by the rotating tool has over the past decade, to some extent, been overcome, and FSW developed to process some steels.

\footnotetext{
${ }^{*}$ Corresponding author:

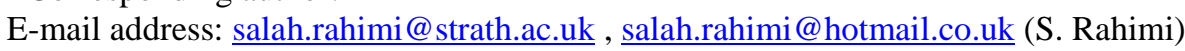

Tel: 0044 (0) 1415345243

Fax: 0044 (0) 1415623387
} 
FSW has been developed to process steels, which has been achieved through improvements in the tools which are capable of withstanding higher flow stresses at higher temperatures, in the range $1000-1200^{\circ} \mathrm{C}$ [3, 5-9]. Austenitic stainless steels were among the first to be studied [5-6], and there is now a growing body of literature demonstrating successful welds in ferritic steels, together with the potential for joining dissimilar steels [7-9]. Also, the lower heat inputs, producing fewer metallurgical changes in the heataffected zone (HAZ) compared to fusion welding, is regarded as an additional advantage for FSW of steels [10]. Generally, the ferritic steel joined by the FSW process has been limited to a thickness of $\leq$ $10 \mathrm{~mm}$. This, for the most part, is a consequence of the tool strength and toughness placing a size constraint on the FSW tool. An approach developed for thicker plate involves passing a tool of slightly greater length than half the thickness of the plate on both sides of the abutted plates in sequence [11-13]. This gives rise to an interaction zone (IZ) where the root of the first pass weld is reprocessed by the second pass on the reverse side of the plate, producing a complex deformation zone. The HAZ's are also affected by the plate reverse side FSW pass. In the first published account of double sided FSW [12], a tungsten tool was used to weld up to $12.7 \mathrm{~mm}$ thick HSLA-65 (ASTM A945) steel plate. It was found that following the procedure laid down by a British standard involving bending to $120^{\circ}$, the $12.7 \mathrm{~mm}$ plate passed the face and root bend test without cracking. Low shear values were recorded in the stir zone, indicated a lower shelf behaviour, which could be attributed to the coarser ferrite microstructure, observed by optical microscopy. A comparison between single and double-sided FSW of DH36 steel has revealed that the latter showed the highest strength, attributed to the observation of 'regular fine acicular ferrite' [13].

Around $12 \%$ of the world tonnage of steel is microalloyed steel, with applications which include bridges and building framework, cranes, ships, and transport [14], often processed by controlled rolling. This may involve both dynamic and static recrystallization and also strain induced precipitation of carbonitrides of niobium and vanadium and possibly titanium carbide, all which influence the mechanical and toughness properties. When they are fine $(10-25 \mathrm{~nm})$, these precipitates provide dispersion hardening and when they are larger $(20-50 \mathrm{~nm})$, depending on their volume fraction, grain refinement through grain boundary pinning [15-17]. Some or all of these processes might be expected may take place during the FSW of microalloyed steel, as has been discussed in a recent report [18].

A variety of terms were used in the literature to describe different microstructural zones observed during FSW of different materials [19]. The material forming the weld undergoes a complex thermo-mechanical treatment as a result of friction generated between the tool and the workpiece. In this process the plastically deformed material under the shoulder is moved by the tool's rotation and sideways movement. For a single pass FSW, the post weld microstructural zones are classified as (i) unaffected base material (BM); (ii) the heat affected zone (HAZ); (iii) the thermo-mechanically affected zone (TMAZ), where the material is subjected to both plastic deformation and the heat generated by the process [19]. The TMAZ extends across the weld from the HAZ on the advancing side (AS) to the HAZ on the retreating side (RS), which has frequently been subdivided to further subzones depending on microstructure. The central part of the TMAZ generally known as the stirred zone (SZ), or nugget (NG), where in some materials such as aluminium, the material undergoes recrystallisation and grain refinement. An area immediately below the upper face of the weld, known as the shoulder affected zone (SAZ), in which the material is subjected to strains induced by the shoulder along the welding direction (WD), in addition to the in-plane strains induced by the tool's rotation. In addition to the above zones in TMAZ, in double-sided FSW studied in this work, there exists a zone in the centre of the stir zone in which the material experiences the welding 
process twice, where the second weld pass is partially (i.e. depending on the probe length) overlapping with the root of the first weld pass [11]. In this study, this region is referred to as the interaction zone (IZ).

The development of crystallographic texture and microstructure evolution during FSW of microalloyed steels, in particular in double-sided FSW, has not been investigated in any detail, and only a few reports are available [13-14, 18, 20]. Most of these studies investigated the relationship between microstructures and mechanical properties, microhardness profile and strengths in the welded joint, rather than the microstructure and crystallographic texture evolutions. This is most likely because the application of FSW to ferrous alloys, including microalloyed steel, with high melting points has been limited due to the high temperatures and critical wear conditions encountered by the rotating tools. Therefore, most studies have focused on developing appropriate tool materials for FSW of ferrous alloys with ability to resist the aforementioned problems [3, 5-9, 11]. Generally, the studies on microstructural evolution during FSW of ferrous metals, having both face-centred cubic (FCC) and body-centred cubic (BCC) crystal structures, are mainly on materials in which solid state phase transformation does not occur during the process. For example the investigations on the microstructure evolution during FSW of pure iron [21], type 409 ferritic stainless steel [22] and the recrystallisation behaviour of type 304L stainless steel [5].

Texture is a useful means of microstructure analysis to understand the major deformation mechanisms acting on the material during FSW. Studying texture evolution during FSW of aluminium alloys showed that $\{110\}<110>$ and $\{114\}<221>$ shear components were dominant with respect to the local shear reference frame [23-24]. Later study on aluminium showed that the texture is entirely simple shear $B / \bar{B}$ and $C$ components with $B / \bar{B}$ in alternating bands, constructing the onion ring structure, across the whole weld [25]. A well-defined $\{11 \overline{2}\}<111>$ shear texture is reported for pure iron subjected to friction stir processing (FSP) [21]. Also, in type 304 austenitic stainless steel after FSP, rotated-cube texture, $\{1 \overline{1} \overline{1}\}<$ $110>,\{\overline{1} 12\}<110>$ and $\{001\}<110>$ were observed [26]. These findings suggest that the shear created by the rotating tool is the main mechanism affecting microstructure and texture development during FSW and FSP. However, observations of weak shear texture and rotated-cube texture in fcc materials imply that extended plasticity mechanisms such as dynamic recrystallisation are active during the process $[23,26]$. The extended plasticity mechanisms and phase transformation have impact on the final microstructure and texture. A recent study on API X 100 grade of linepipe steel [27] that undergoes phase transformation during FSW, found that the material in TMAZ experiences a complex microstructure evolution. These are observed to be phase transformation in the SZ, continues dynamic recrystallisation in the transition zone between the TMAZ and the HAZ, and rearrangement of low angle grain boundaries in the HAZ. Despite the shear texture caused by FSW in the SZ, the texture was observed to be random, and the reason has been attributed to the weakening effect of phase transformation on the shear texture [27].

The FSW of microalloyed steel involves thermal impact, thermo-mechanical processing and phase transformation, which are still not clearly understood. The solid state phase transformation dictates the physical and mechanical properties of ferrous alloys, and information is lacking in this respect for FSW of microalloyed steels. This paper aims to present a clear understanding of the evolution of crystallographic texture and microstructural changes in a double-sided friction stir welded microalloyed steel of type EH46. 


\section{Experimental Procedure}

\subsection{Material and processing}

The double-side weld was produced at TWI from two plates of EH46 microalloyed steel with $14.5 \mathrm{~mm}$ original thickness. The chemical composition is provided in Error! Reference source not found.. A typical Trifalt ${ }^{\mathrm{TM}}$ design MegaStir tool with a $25 \mathrm{~mm}$ shoulder diameter, $8 \mathrm{~mm}$ pin length, $4 \mathrm{~mm}$ pin base diameter and a $45^{\circ}$ tapered probe from either side was used, where the rotation direction was counter clock wise $(\mathrm{CCW})$. The tool had a tungsten carbide shank with a probe made from polycrystalline boron nitride (PCBN). The weld was produced under force control in two passes. The first weld pass was made at rotational speed of $200 \mathrm{rpm}$, transverse speed of $125 \mathrm{~mm} \mathrm{~min}^{-1}$ and an average downward axial force of $55 \mathrm{kN}$. The tool was then moved over the BM, and the plate was cooled, unclamped and turned after the first pass, so that the second pass started at ambient temperature. The second weld pass was then continued with the same tool at $180 \mathrm{rpm}$ and identical transverse speed and downward axial force as those of the first weld pass. Both the tool and the weld were shielded by maintaining an Ar atmosphere using a gas cup located around the tool to minimize surface oxidation during the welding process. A small reduction in the rotation speed for the second weld pass was to prevent tool overheating. This has resulted in $10 \%$ reduction in the heat input which was calculated from processing factors such as travel speed, tool rotation speed and torque [28].

Table 1: Nominal chemical composition for EH46 microalloyed steel used in this study (wt\%)

\begin{tabular}{|c|c|c|c|c|c|c|c|c|c|c|c|c|c|c|}
\hline Element & $\mathbf{F e}$ & $\mathbf{C r}$ & $\mathbf{N i}$ & $\mathbf{S i}$ & $\mathbf{M n}$ & $\mathbf{C}$ & $\mathbf{P}$ & $\mathbf{N}$ & $\mathbf{S}$ & $\mathbf{A l}$ & $\mathbf{N b}$ & $\mathbf{V}$ & $\mathbf{T i}$ & $\mathbf{M o}$ \\
\hline $\mathrm{wt} \%$ & Bal. & 0.01 & 0.02 & 0.45 & 1.46 & 0.12 & 0.014 & 0.005 & 0.003 & 0.05 & 0.03 & 0.07 & 0.004 & $<0.01$ \\
\hline
\end{tabular}

\subsection{Microstructure characterisation}

Electron backscatter diffraction was used for microstructure characterisations. For the EBSD analysis, a sample with $30 \mathrm{~mm} \times 14.5 \mathrm{~mm}$ dimensions was cut from the double-sided weld cross-section, in the plane perpendicular to the welding direction (WD), and mechanically ground by silicon carbide (SiC) emery paper with grit size of 240, 400, 600 and 1200 successively, then polished by 6 and $1 \mu \mathrm{m}$ lubricate diamond paste and $0.05 \mu \mathrm{m}$ colloidal silica suspension. The mirror finished sample was then subjected to a final stage of vibratory polishing for a period of 3 hours using diluted colloidal silica (i.e. 50\% deionised water) suspension. The acquisition of EBSD maps were carried out using a fully automated HKL-EBSD system interfaced to a FEI Quanta-250 field-emission gun scanning electron microscope, with an accelerating voltage of $20 \mathrm{kV}$ and a $100 \mu \mathrm{m}$ dia. aperture. The acquisition time was set to $40 \mathrm{~ms}$, collecting at least 2 frames for each point. Orientation mapping was performed initially, across the second weld pass in the probe dominated area, starting from the BM on far RS side and terminating on far AS side, with $0.5 \mu \mathrm{m}$ step size covering an area of $14 \mathrm{~mm} \times 0.5 \mathrm{~mm}$, and secondly in the middle of the second weld pass, starting from the SAZ to the centre of IZ (i.e. overlapped area), with $0.4 \mu \mathrm{m}$ step size covering an area of $8.4 \mathrm{~mm} \times 0.4 \mathrm{~mm}$. Additionally, individual high resolution maps with $0.2 \mu \mathrm{m}$ step size and $280 \mu \mathrm{m} \times 260 \mu \mathrm{m}$ area each, have been collected from the centreline of the SZ in the probe dominated area of both weld passes and from the centre of the IZ. The locations of these maps are visible in Figure 2 following etching with nital solution for optical microscopy (OM) inspection, since these areas subjected to EBSD scanning are not etched sufficiently. In all cases, a minimum of $70 \%$ of the scanned areas were indexed. Following the EBSD scans, the surface was etched with a $4 \%$ nital solution for 15 seconds and inspected by OM. 


\subsection{Microhardness Measurement}

Following the microstructure characterisations, a Zwick/Roell microhardness testing machine was used to measure a hardness map on the sample cross section, including the BM and different zones of the weld. These measurements were acquired using a diamond shaped Vickers indenter by applying 1000 gf with $10 \mathrm{~s}$ delay. Indentations were made on a rectangular grid covering the weld cross section, with $1 \mathrm{~mm}$ spacing in both normal direction (ND) and transverse direction (TD) between indentations, except in the IZ with $0.5 \mathrm{~mm}$ spacing, and $\approx 250 \mu \mathrm{m}$ distance between the closest indentations and edges of the sample.

\subsection{Residual Stress Measurement}

The residual stress components were measured by X-ray diffraction (XRD) using a PROTO-LXRD diffractometer and the $\sin ^{2} \psi$ method [29]; the stresses were calculated from the strains of the $\{211\}$ Bragg reflection at $156^{\circ}$ Bragg angle, assuming Young's modulus of $215 \mathrm{GPa}$ and Poisson's ratio of 0.275. The measurements were in two perpendicular directions of the TD and the ND. These measurements were performed on a rectangular grid at equally spaced points, $1 \mathrm{~mm}$ distance in both ND and TD, encompassing the entire double-sided weld and BM on either sides of the weld. For each point in both directions, 10 measurements with $1 \mathrm{~s}$ exposure time for each measurement were performed. A round collimator with $2 \mathrm{~mm}$ radius and eleven $\psi$-off set angles in the range of maximum $\pm 33^{\circ}$ were employed.

\section{Results}

\subsection{Base Material}

Figure 1a shows an OM appearance of the BM containing banded ferrite and pearlite microstructure. The $\mathrm{BM}$ microstructure consisted of near-equiaxed ferrite grains with an average grain size of $18 \mu \mathrm{m}$, and pearlite colonies with an average grain size of $5 \mu \mathrm{m}$. The $\mathrm{BM}$ does not have a homogeneous microstructure as the average grain size of ferrite grains at some regions has been measured to be $25 \mu \mathrm{m}$. Figure 1b shows orientation image map (OIM) of the BM using inverse pole figure (IPF) colouring with respect to the normal direction (ND). The BM has a texture, which is shown in Figure 1c in the form of $\{100\}$ and $\{110\}$ pole figures. It contains $<110>$ poles parallel to the rolling direction (RD) with heterogeneous distribution, indicating the presence of RD fibers, resulting from hot-band rolling of the manufacturing process. Note that the WD is parallel to the RD of the original plate of material. 


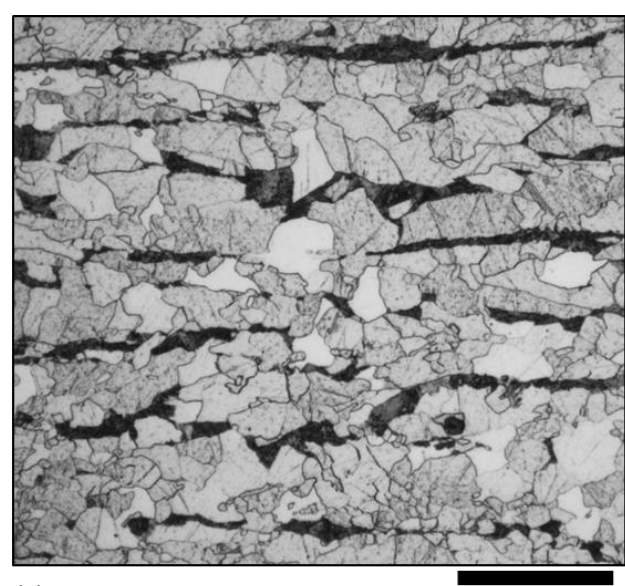

(a)

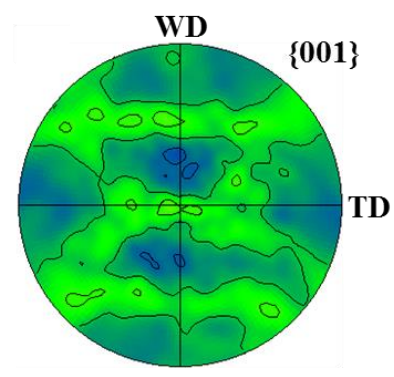

(c)

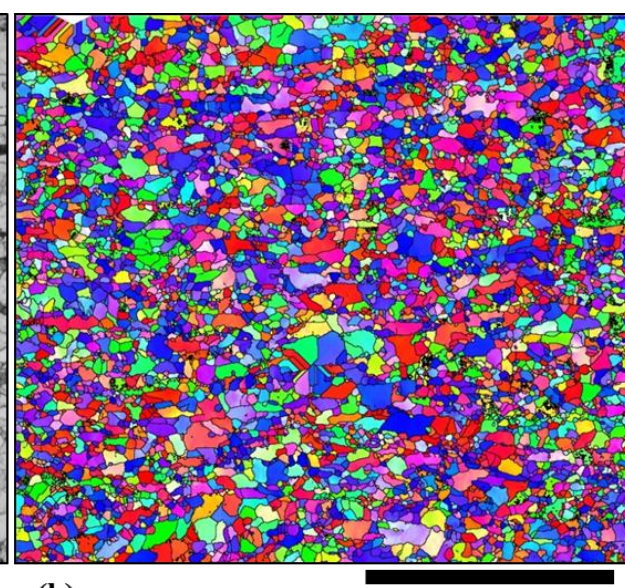

(b)

$200 \mu \mathrm{m}$
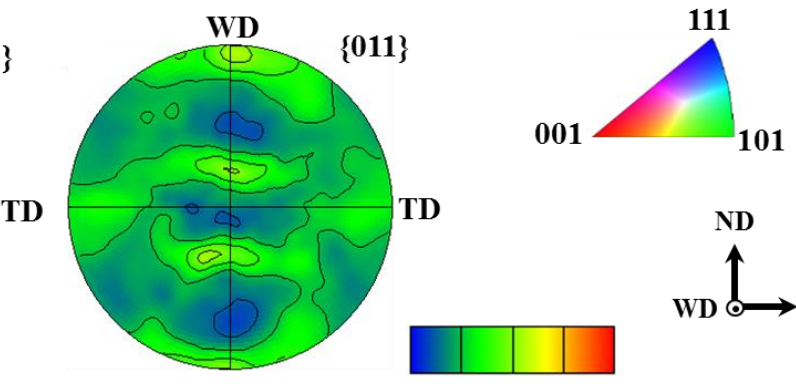

TD
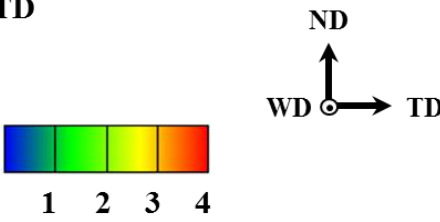

TD

Figure 1: Microstructure characteristics of the BM, (a) OM micrograph, (b) EBSD map with IPF colouring with respect to the ND of the BM. The rolling direction (RD) of the original plate is parallel to the welding direction (WD), (c) $\{001\}$ and $\{011\}$ pole figures showing the initial textures in BM.

\subsection{Weld Microstructure}

Figure 2 is an optical micrograph of the weld cross-section following the nital etching. The welded area can be distinguished from the BM due to its characteristic hour-glass shape appearance that is darker than the rest of the surface. The advancing side (AS) and retreating side (RS) of both weld passes are shown in Figure 2. AS and RS of both weld passes are on the same side of the micrograph. The slope of the weld in the probe dominated area has been measured to be $47^{\circ}$ on either side of both weld passes from the vertical, which is not equal to the $45^{\circ}$ pin angle, implying that the effective tapering of the weld is larger than actual tapering of the probe. A region can be seen in the centre of the stirred zones with approximately $2-2.5 \mathrm{~mm}$ thickness that appears to be equivalent to the overlapping section of the probe during second weld pass on the root of welded material from the first pass, that is referred to as the IZ hereafter. Note that the white tiles, comprising the cross-shaped feature in the middle of the second weld pass and the individual tiles in the middle of the SZs and the IZ, are the areas from which the EBSD maps are acquired, and not been etched by the nital solution. Highlighted in Figure 2 by open squares are the regions from which $\mathrm{OM}$ micrographs were taken and shown in Figure 3a through to Figure 3f. 


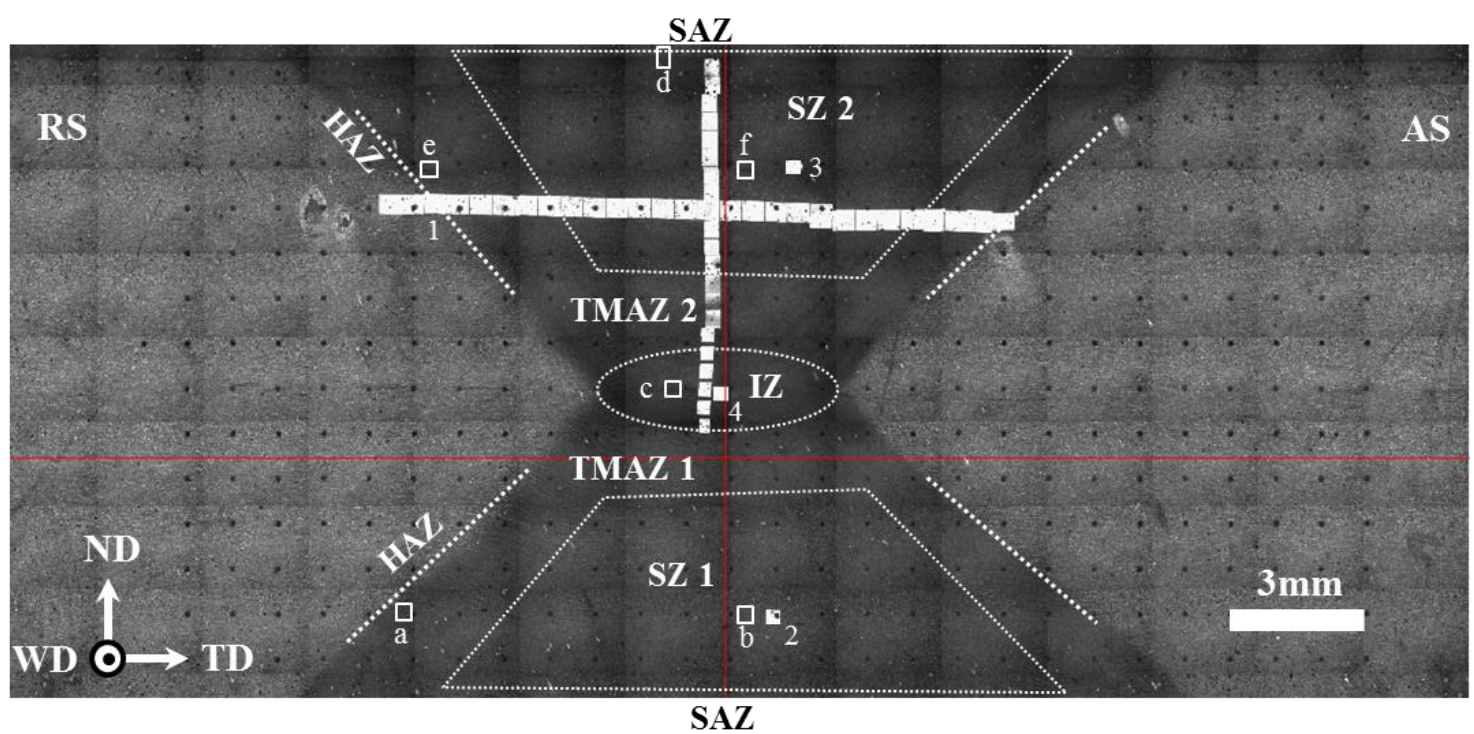

Figure 2: Optical micrograph of the transverse cross-section of the double-sided friction stir welded plate. The non-etched white regions are the areas where EBSD maps are obtained. The welding direction (WD) is perpendicular to the plane of the micrograph. Note that the first weld pass is at the bottom and the second pass is at the top of the micrograph. Different regions are distinguished by adding 1 and 2 as suffix respectively for the first and second weld passes. The advancing side (AS) and retreating side (RS) of both weld passes are identical. Thin dashed white lines, drawn between HAZ and TMAZs, are at $\pm 47^{\circ}$ from the vertical. Locations labelled ' $a$ "' through ' $f$ ', are the positions of micrographs presented in Figure 3(a) - (f), respectively. Those labelled ' 1 '" through " 4 " respectively show the positions of high resolution EBSD maps presented in Figure 4(a)-(d).

The double-sided weld in this study consists of the unchanged BM, HAZ and TMAZ. The TMAZ can further be classified into different subzones of SAZ, SZ and IZ, depending on the observed microstructure. These zones and subzones are schematically shown in Figure 2. The term 'stirred zone' (SZ) is perhaps not technically correct as the entire TMAZ including the SZ is experiencing the stirring process, but it has been used for the sake of simplicity. Figure 3 and Figure 4 respectively show high resolution OM micrographs and EBSD maps using inverse pole figure (IPF) colouring with respect to the normal direction (ND), obtained from different regions of the weld highlighted in Figure 2.

A detailed examination of the separate weld region shows that the BM microstructure persists into the HAZ, where close to the border with TMAZ, clusters of fine grains are observed penetrating into the network of larger BM grains (see Figure 4a). A transient region in TMAZ, between HAZ and SZ on both AS and RS sides, with approximately $1 \mathrm{~mm}$ thickness is observed, that has uniform equiaxed ferrite grains with a fine grain size of $\sim 3$ to $5 \mu \mathrm{m}$ (see Figure $3 \mathrm{a}$ and e, Figure $4 \mathrm{a}$ and Figure $5 \mathrm{c}$ ). The SAZ for both weld passes is a region with 200-250 $\mu \mathrm{m}$ thickness, having uniform equiaxed ferrite grains with an average grain size of 3 to $5 \mu \mathrm{m}$. In the IZ, where the second weld pass overlaps partially with the first weld pass, uniform ultrafine ferrite grains $(\sim 0.8 \mu \mathrm{m})$, have been observed. The overlapping process has resulted in significantly finer grain size $(\sim 0.8 \mu \mathrm{m})$ compared to those of the SAZ and transient zones between TMAZ and HAZ on both AS and RS (see Figure 3c and Figure 4d). Figure 5 shows the grain size distributions for the SZs of both weld passes, TMAZ and the IZ.

The microstructure in the SZs is bainitic/ferritic with acicular grain morphology that widens significantly towards the SAZ in both weld passes (see Figure 3 and Figure 4). In the SZ the microstructure is not uniform, as the percentages of bainite and ferrite changes with position within the SZ. The centre of the SZ is predominantly bainitic /acicular ferrite with some ferrite grains along the bainite colonies (see 
Figure $3 \mathrm{~b}$ and $\mathrm{f}$ ). The fraction of ferrite grains increases, moving from the centre of the SZ toward the edges, in all directions. Also, the SZ microstructure is not symmetrical around the centre of the weld. This manifests itself in the maximum concentration of bainite in the SZ of both weld passes, drifting toward the AS and therefore not coinciding with the centre of the weld. In both weld passes, the SZ is surrounded by TMAZ of fine equiaxed ferrite grains. A transition from fully acicular bainitic/ferritic microstructure in the SZ to a fully ferritic microstructure in the TMAZ, is sharp and abrupt on the AS and SAZ sides. In contrast, it is rather gradual on the RS and toward the IZ. From the microstructural observations, the SZ in the first weld pass appears to be slightly wider than the SZ in the second weld pass. This is probably due to the slightly higher probe rotational speed of the first weld pass (200 rpm) compared to that of the second pass (180 rpm).

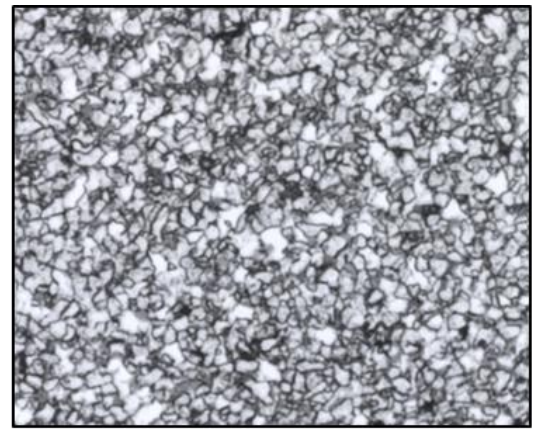

(a)

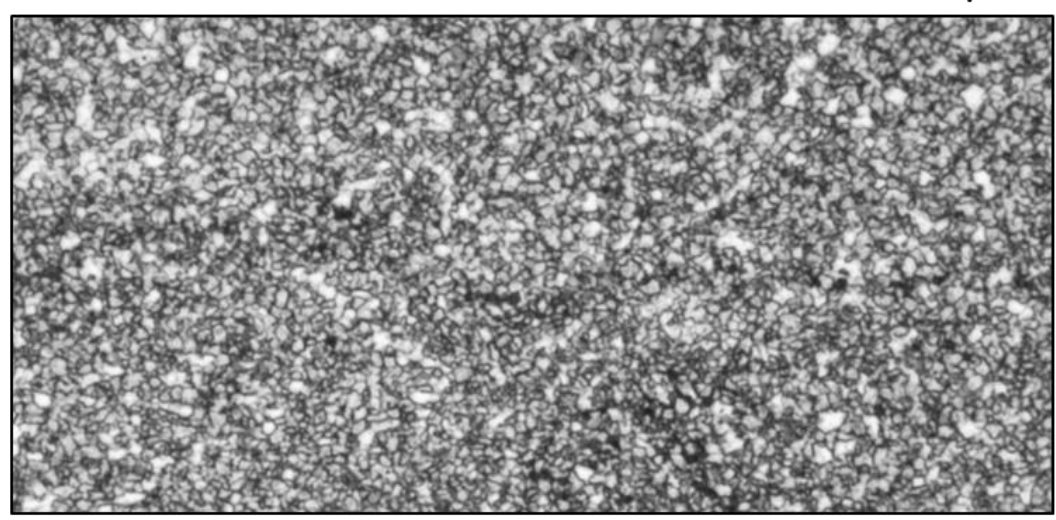

(c)

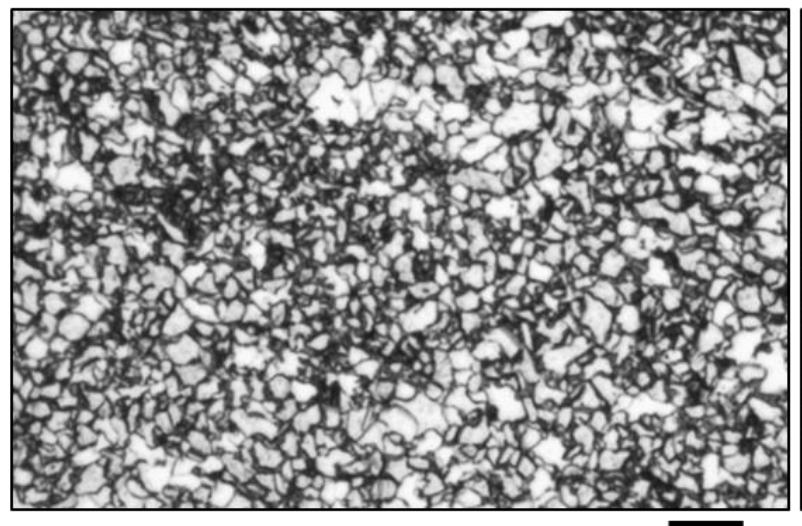

(e)

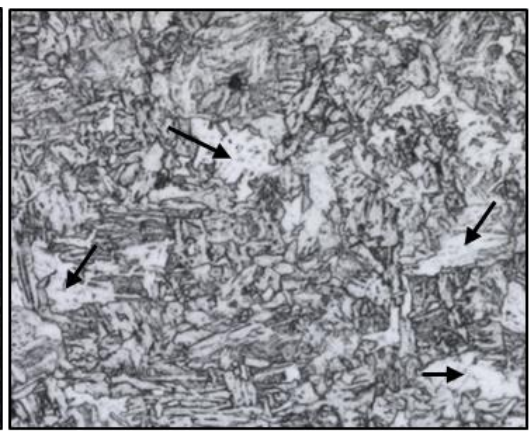

(b)

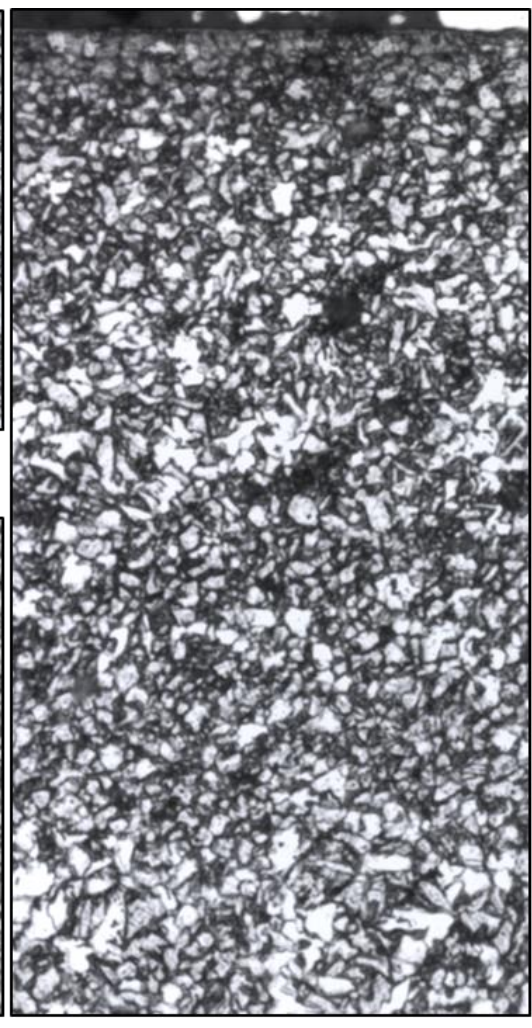

(d)

$10 \mu \mathrm{m}$

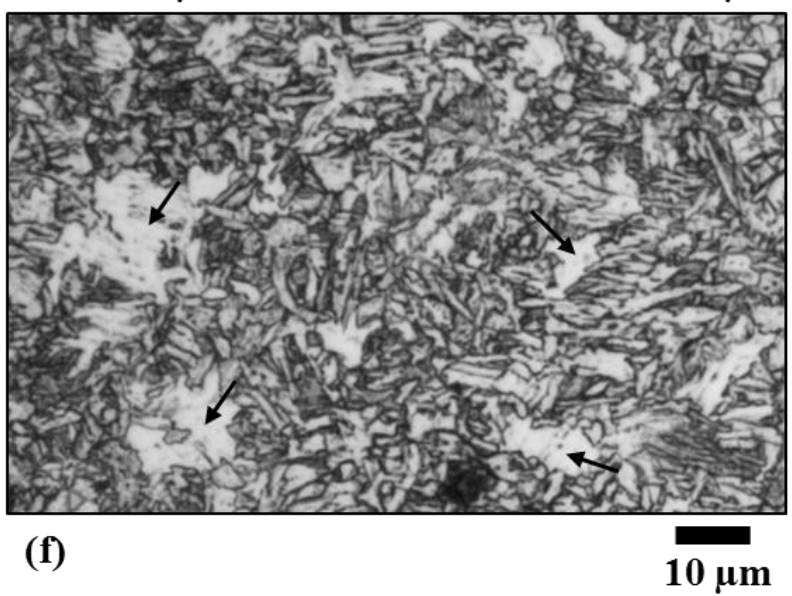

$10 \mu \mathrm{m}$

Figure 3: Optical micrographs of the etched microstructure for different regions of the weld, (a), TMAZ of the first weld pass, (b) centre of the SZ in the first weld pass, (c) the IZ, (d) SAZ of the second weld pass, (e) TMAZ of the second weld pass, and (f) centre of the SZ of the second weld pass. The arrows in (b) and (f) are pointing at ferrite grains along the bainite colonies. 


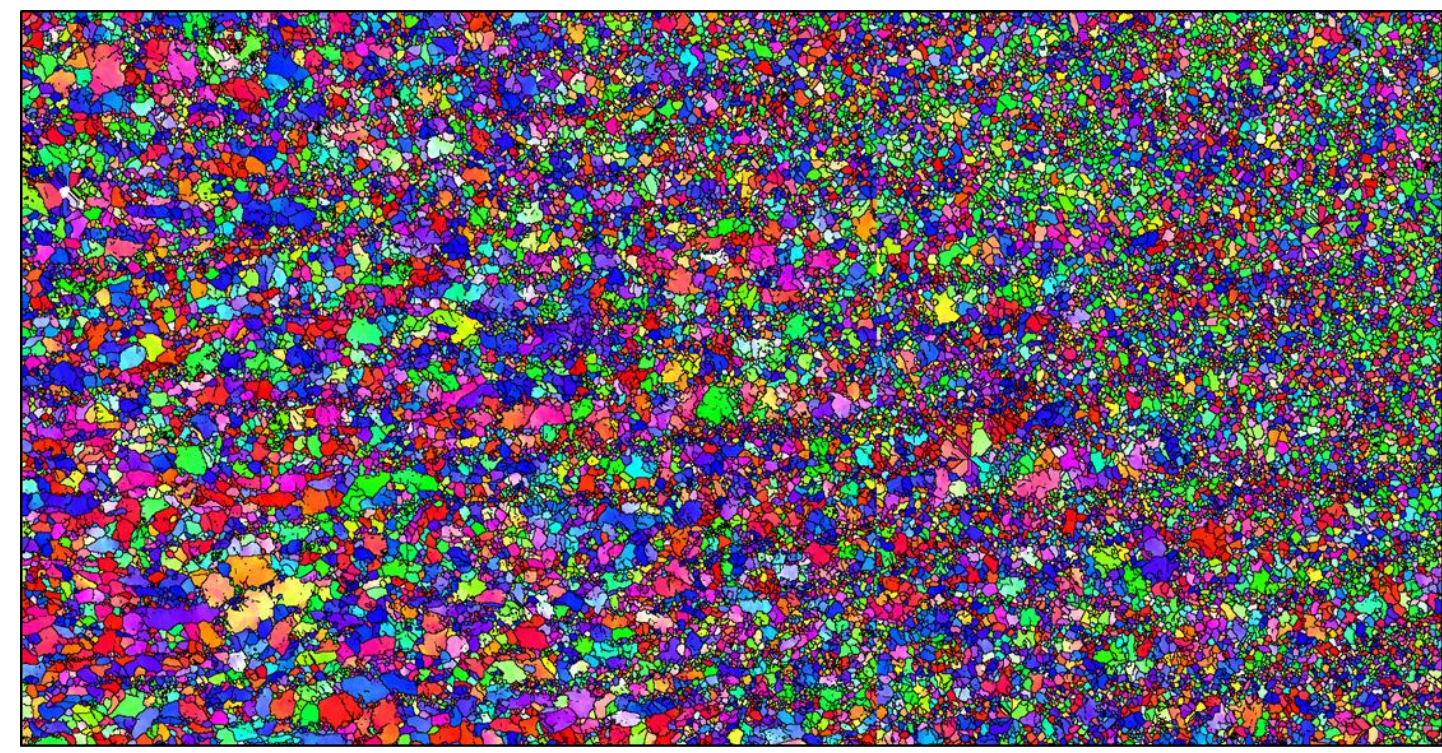

(a)

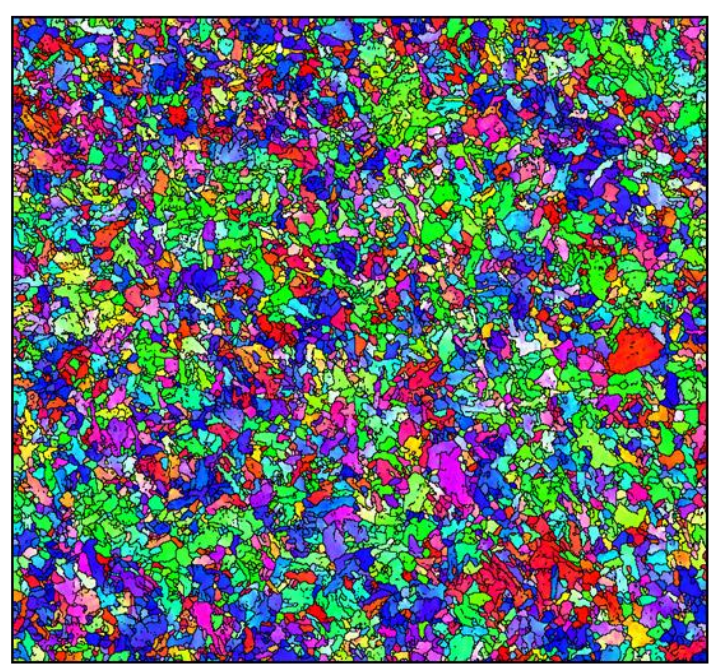

(b)

$100 \mu \mathrm{m}$

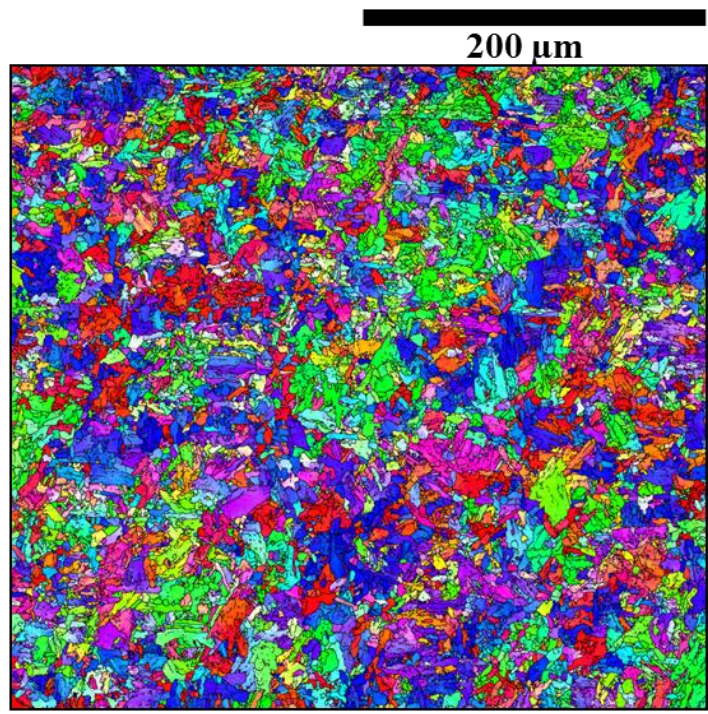

(c)

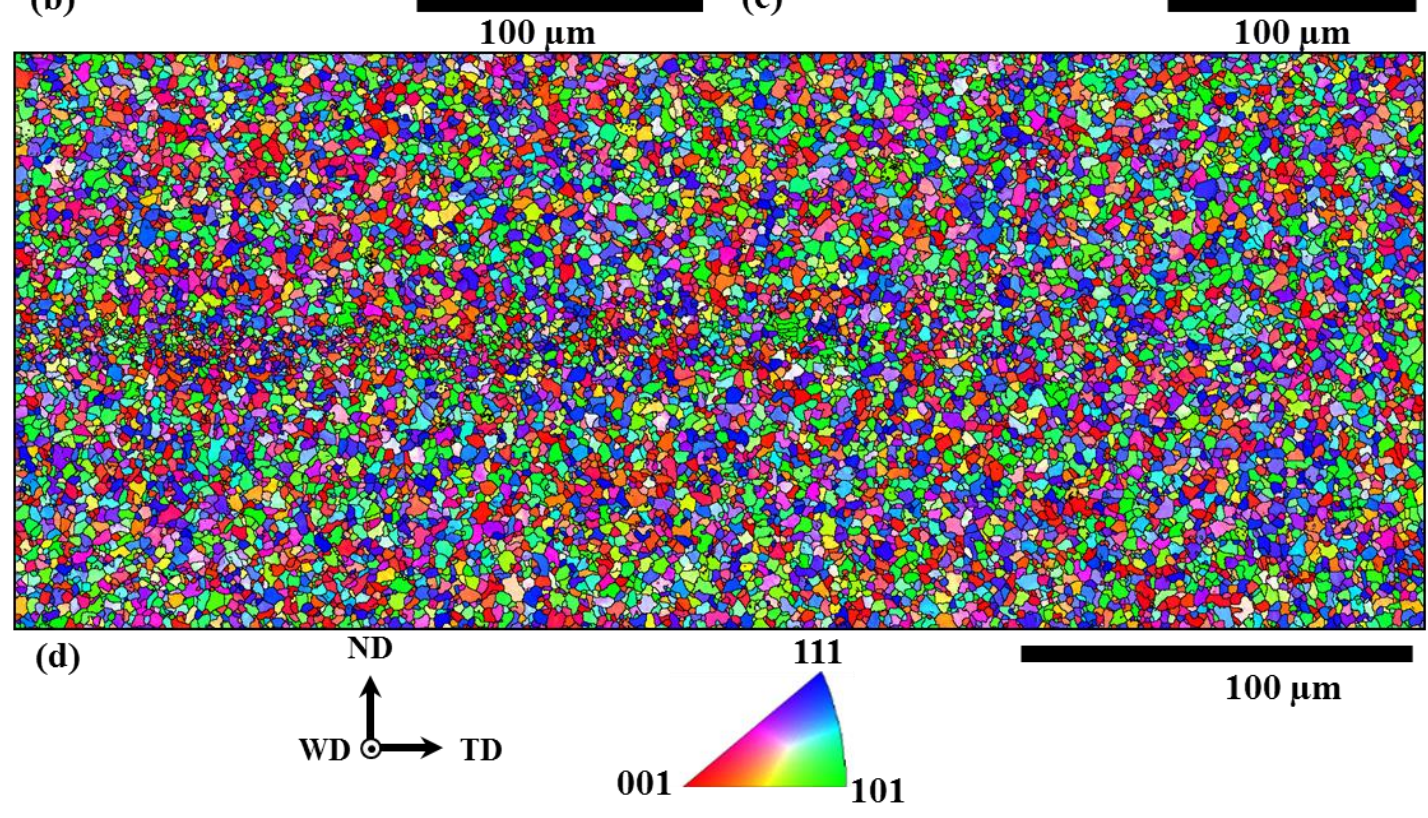

Figure 4: High resolution EBSD IPF colouring maps with respect to the ND of (a) a region between HAZ and TMAZ of the second weld pass, (b) centre of SZ of the first weld pass, (c) centre of SZ of the second weld pass, and (d) centre of the IZ. See Figure 2 for the positions of EBSD maps. 


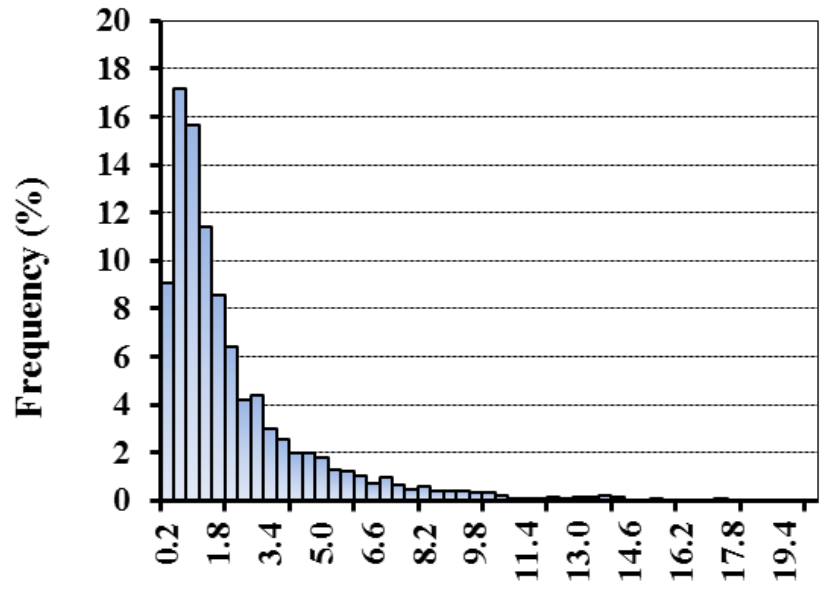

(a)

Grain Size $(\mu \mathrm{m})$

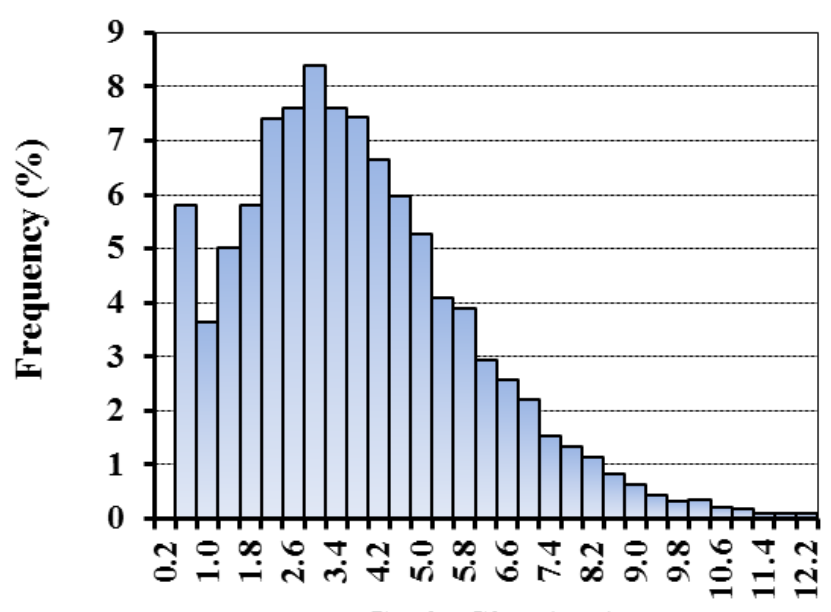

(c)

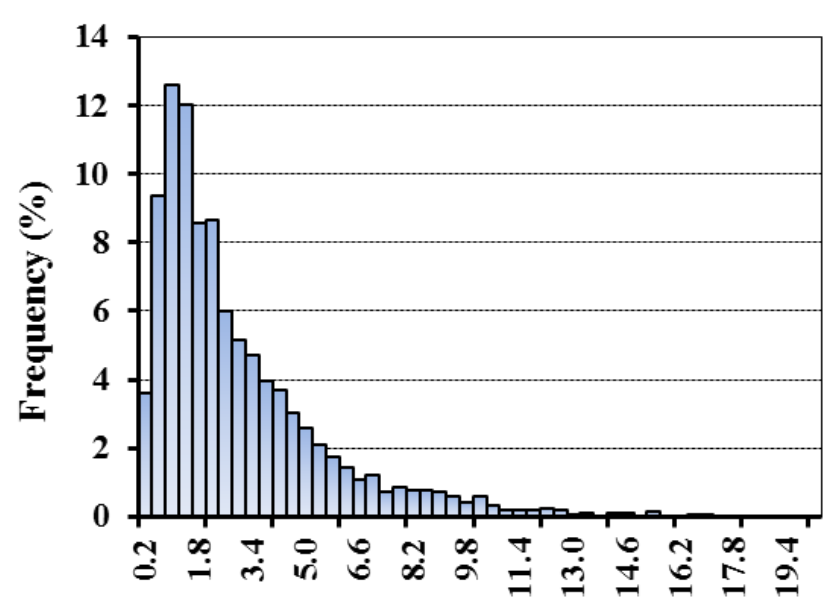

(b)

Grain Size $(\mu \mathrm{m})$

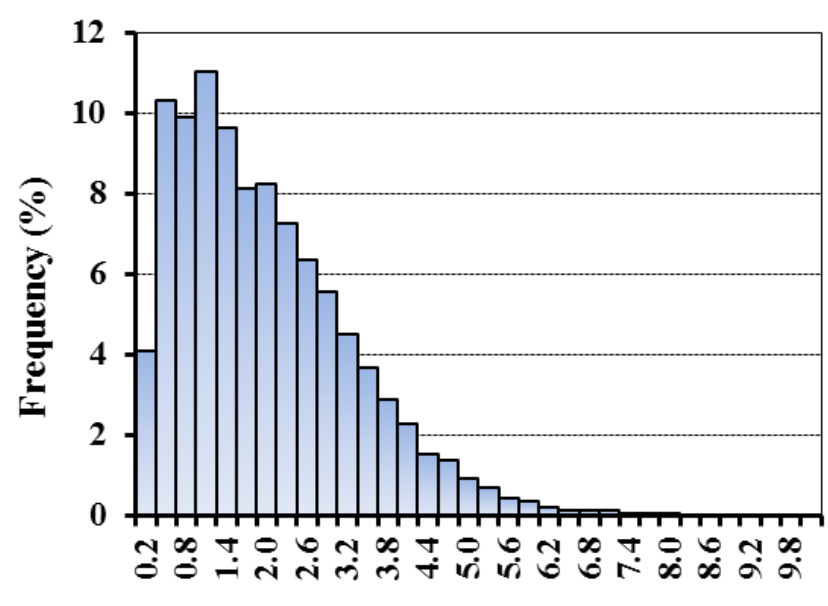

(d)

Grain Size ) $\mu \mathrm{m})$

Figure 5: Grain size distributions of (a) the SZ of the first weld pass, (b) the SZ of the second weld pass, (c) TMAZ, and (d) the centre of IZ.

\subsection{Weld Microhardness}

Figure 6 shows the microhardness map of the weld cross-section along with the plot of microhardness profiles across both weld passes and the IZ from BM on RS, to BM on AS. Optical micrographs of a typical microhardness indentation in each of the major zones are also shown in Figure 6. The typical hardness of the BM ranged from 180 to $200 \mathrm{HV}$, while the hardness in the HAZ increased by approximately 15 to $20 \mathrm{HV}$, compared to that of the BM. In the region of the TMAZ with a fine ferrite grain size (i.e. the area surrounding the SZ in both weld passes), hardness increased to above $250 \mathrm{HV}$. However, in the ultrafine ferrite IZ, the hardness is the lowest among the weld zones at a level that is comparable to the hardness of the HAZ. The hardness in both weld passes is the highest in the SZ, with the peaks in the centre of the SZ, $\approx 320 \mathrm{HV}$ in the first weld pass and $\approx 300 \mathrm{HV}$ in the second weld pass, decreasing to $\approx 250 \mathrm{HV}$ toward the border of the SZ with TMAZ. Overall, the hardness in the SZ of the first weld pass is higher, and is spread over a larger area, than that of the second weld pass. This is in a good agreement with the results of microstructure characterisations showing that the bainitic/ferritic region was larger in the first weld pass due to a slightly higher probe rotational speed. 


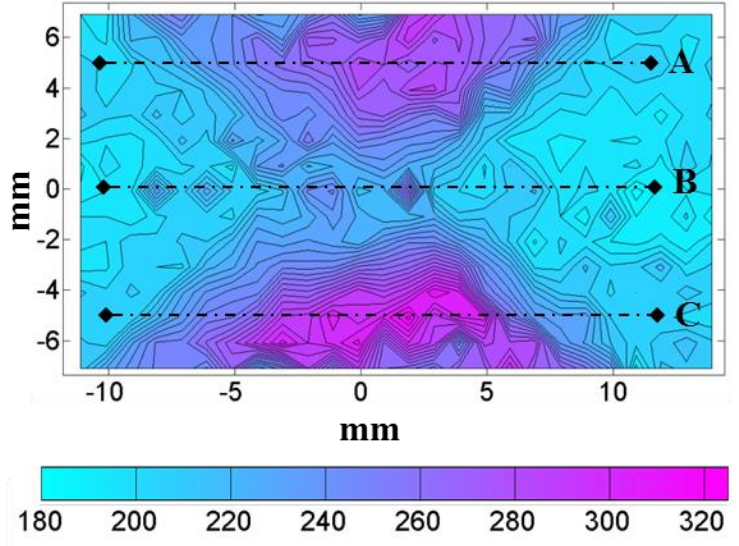

(a)

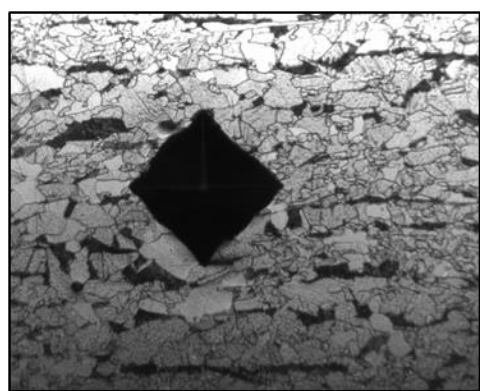

(c)

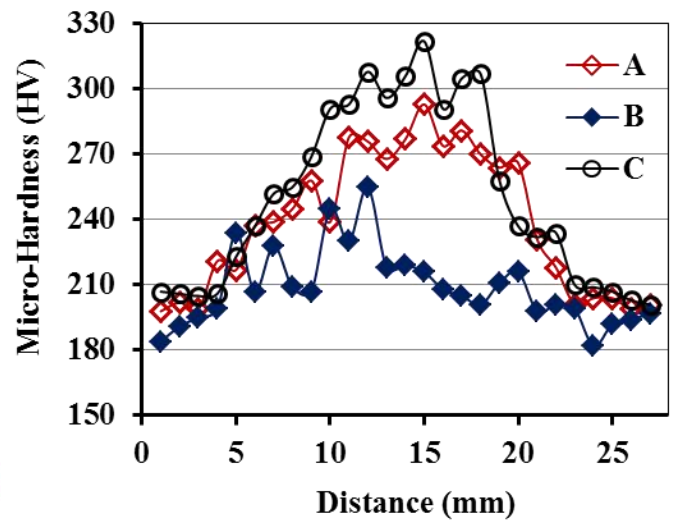

(b)

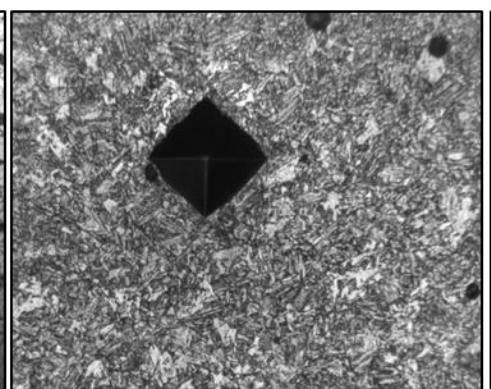

(d)

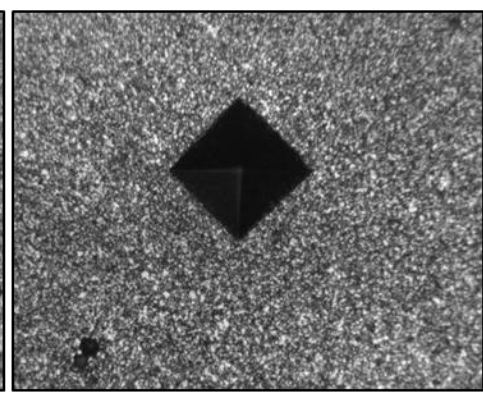

(e)

$100 \mu \mathrm{m}$

Figure 6: (a) Microhardness map of the double-sided weld cross-section including the BM, HAZ and TMAZ, (b) Profiles of the microhardness along the lines shown in (a), and (c), (d) and (e) are typical microhardness indentations made on the BM, centre of $\mathrm{SZ}$ and IZ, respectively.

\subsection{Weld Microtexture}

Figure $7 \mathrm{a}$ and $\mathrm{b}$ show the orientation image maps (OIM) using inverse pole figure (IPF) colouring with regard to the ND across the second weld pass in the probe dominated area, and from the SAZ to the centre of IZ, respectively. Their corresponding $\{110\}$ pole figures of $500 \mu \mathrm{m}$ wide segments for the former and $400 \mu \mathrm{m}$ wide segments for the latter, are also provided. The BM microstructure persists into the HAZ, where the texture becomes weaker and rotates few degrees $\left(\approx 5^{\circ}\right)$ clockwise about ND. The transient region between HAZ and TMAZ, with uniform fine equiaxed ferrite grains, has an entirely different texture distribution than that of the BM. After TMAZ, the texture is similar, but with different intensities and a clear systematic rotation across the whole SZ, and the dominant IPF colours change with position in the weld. The OIM map in Figure 7a clearly shows near $<101>$ (green) grain orientation, in a region of $\sim 1 \mathrm{~mm}$ thickness in TMAZ on far RS of the SZ. Beyond this region to the centre of the SZ, the alternating texture becomes less apparent. Similar evolution can be observed from the centre of SZ to the other side of the weld (i.e. AS), with the only difference being that the transition from SZ to TMAZ is much sharper in the AS than the RS.

At the extreme RS side of SZ, the strong (110) pole of the texture lie almost in the TD plane tilted approximately $45^{\circ}$ from the ND. The (110) pole then rotates around the ND as a function of distance from the centre of the weld, keeping the tilted angle of $45^{\circ}$ from the ND, such that the (110) poles in the centre lie in the WD plane. Also, at the extreme AS side, once again, the (110) plane lies in the TD plane with $180^{\circ}$ rotation from the RS side. 
The OIM taken from the SAZ to the centre of the stir zone (Figure $7 \mathrm{~b}$ ) shows a region with $200-250 \mu \mathrm{m}$ thickness from top of the weld with a weaker shear texture in comparison to that of the centre of SZ. From the SAZ onward, down to a distance of $\approx 6.4 \mathrm{~mm}$ from top of the weld (i.e. transition between $\mathrm{SZ}$ and TMAZ), the texture looks similar, with a small change in intensity as a function of position from SAZ.

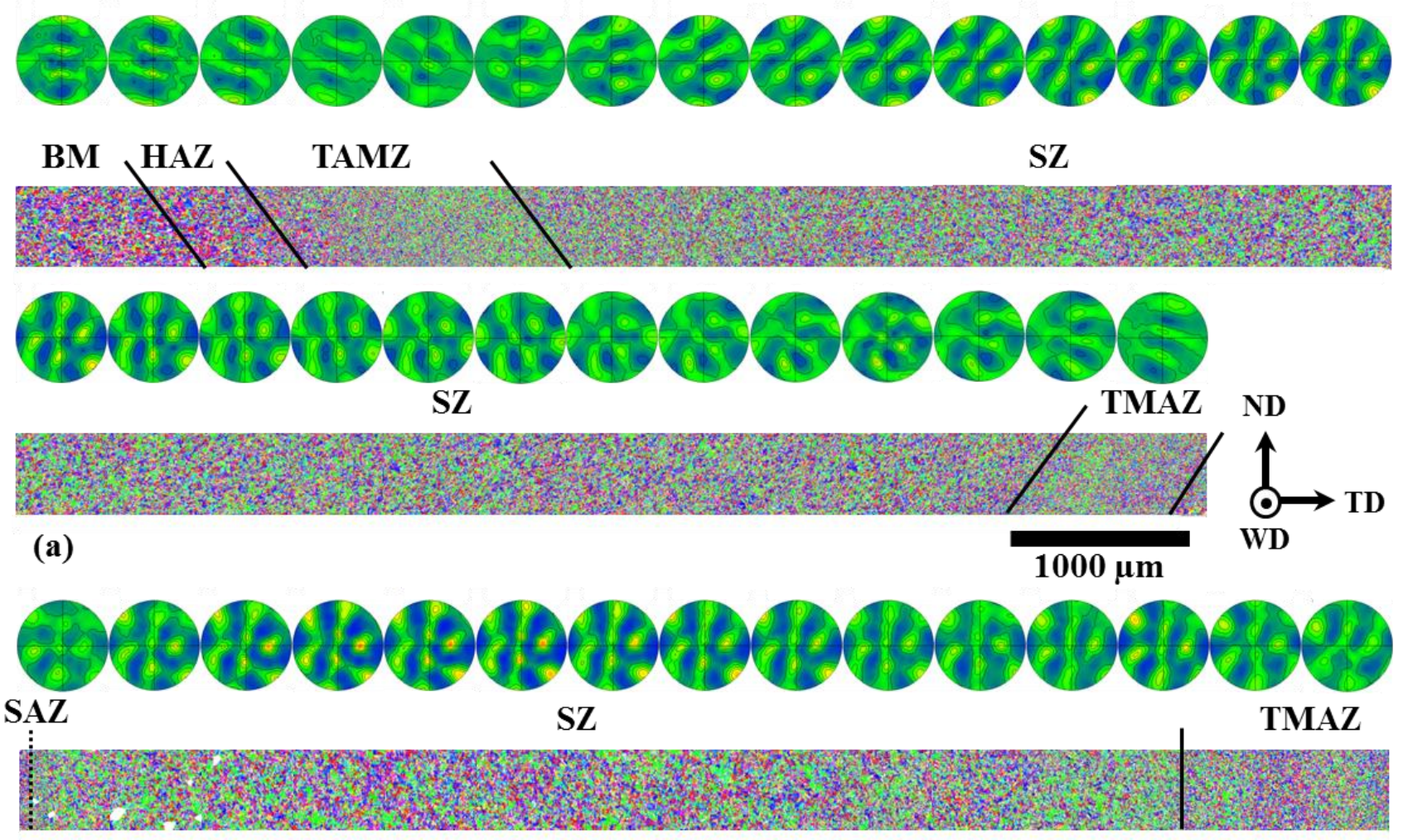

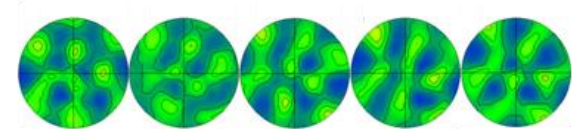

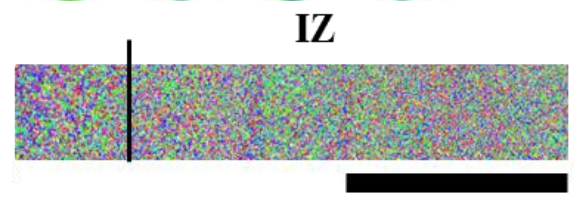

(b)

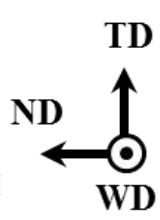

$800 \mu \mathrm{m}$

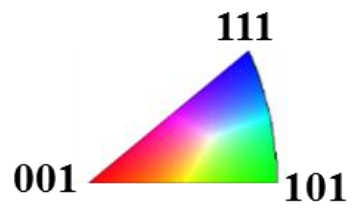

101
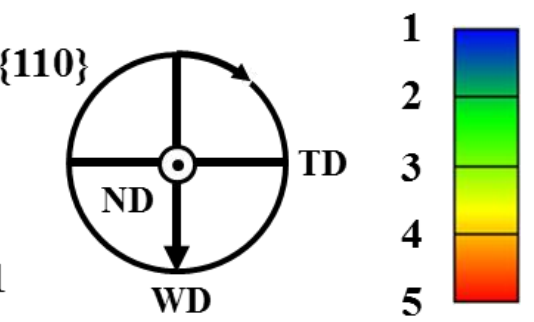

Figure 7: EBSD IPF colouring maps with respect to the ND (a) across the TMAZ and SZ of the second weld pass, and (b) from the SAZ to the centre of IZ of the second weld pass, with their associated (110) pole figures in $500 \mu \mathrm{m}$ steps for (a) and $400 \mu \mathrm{m}$ steps for (b) along the whole maps. The positions of both maps are indicated in Figure 2. For all the pole figures the ND is in the centre and the WD at the bottom.

\subsection{Weld Residual Stress}

Figure $8 \mathrm{a}$ and $\mathrm{b}$ show the transvers (along the weld's TD) and through-thickness normal (along the weld ND) residual stress maps, obtained from the weld cross-section, respectively. The magnitudes and distributions of both residual stress components change with position in the weld. The uncertainties associated with these measurements are in all cases $\pm 20 \mathrm{MPa}$. The transverse residual stress of both weld passes is compressive in the SZ, with the maximum stress of $-340 \pm 20 \mathrm{MPa}$ in the first weld pass and $167 \pm 18 \mathrm{MPa}$ in the second weld pass. This shows that the residual stress in the SZ of the first weld pass is larger than that of the second weld pass by over an order of magnitude. The transverse residual stress is tensile in the IZ, with a maximum of $146 \pm 16 \mathrm{MPa}$ in the centre of the overlapped area. This residual 
stress reduces to the same level as that of the BM with an average of $-50 \pm 10 \mathrm{MP}$, over the distance from the centre of the weld. Note that the measured TD residual stress in TMAZ's of both weld passes, between the IZ and SZs, is close to zero over a larger area in the second weld pass.

Figure $8 \mathrm{~b}$ shows that the normal residual stress in the IZ and TMAZ of both weld passes is close to $0 \pm 20$ $\mathrm{MPa}$. These zones are those in which ultrafine and fine ferrite have been observed (Figure $3 \mathrm{a}$, c, e and Figure $4 \mathrm{a}, \mathrm{d}$ ). The normal residual stress in the $\mathrm{SZ}$ of both weld passes are compressive with magnitudes ranging from $-60 \pm 20 \mathrm{MPa}$ to $-80 \pm 20 \mathrm{MPa}$. This stress component in the SAZ of both weld passes and the $\mathrm{BM}$ appears to be largest compressive with a maximum value of $-160 \pm 20 \mathrm{MPa}$.
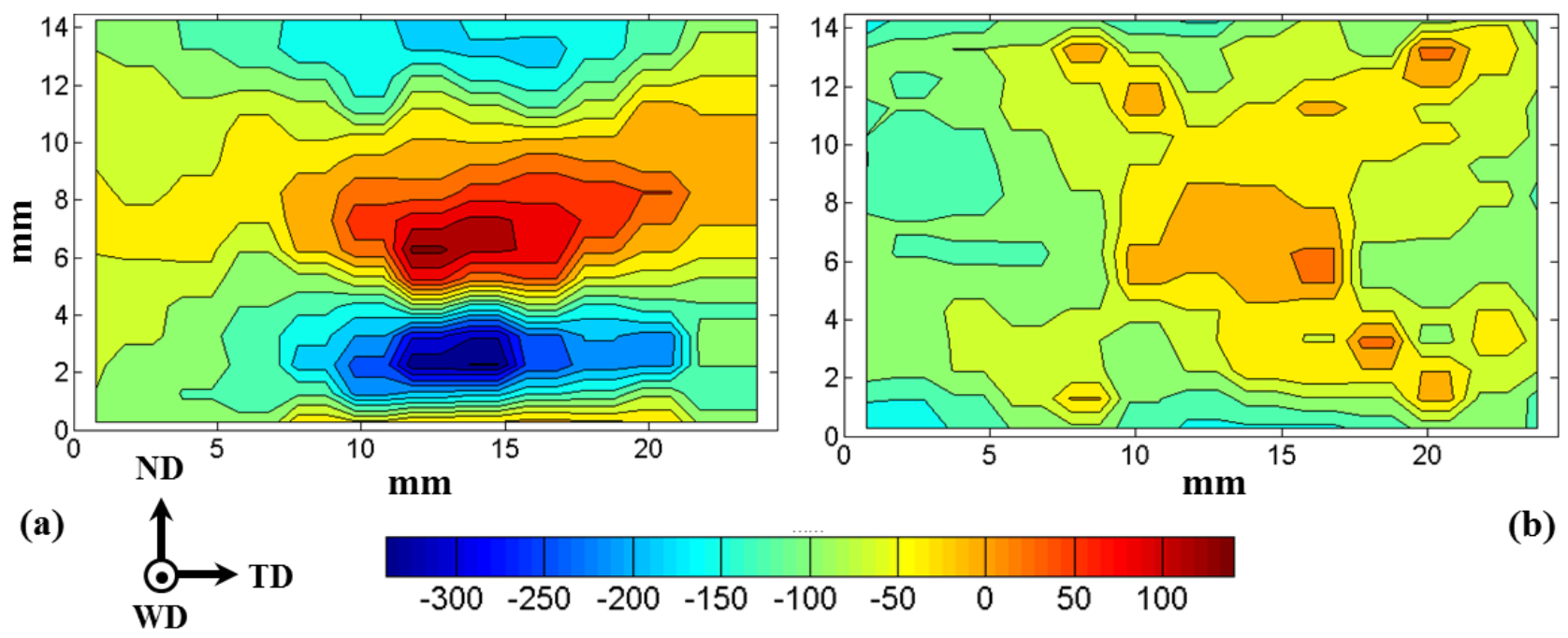

Figure 8: Residual stress distribution, measured by XRD, on the double-sided weld cross section, (a) along the TD, and (b) along the ND.

\section{Discussion}

\subsection{Microstructure Evolution}

This work started as a feasibility study with the aim of understanding the development of microstructure related to the mechanical and toughness properties in double sided FSW of microalloyed steel [18]. This extension explored the development of microstructure and crystallographic texture to understand the dominant deformation mechanisms during welding of plate which was too thick for joining by a single pass.

Ferritic steels have been observed to develop characteristic fiber textures, such as the so-called $\alpha$-RD fiber, $\{$ hkl $\}\langle 110\rangle$, where $\{h k l\}$ is normal to the surface of the plate and $\langle$ uvw $\rangle$ is parallel to the RD [30]. A previous investigation [30] reported that the texture and microstructure of ferritic steels are very inhomogeneous throughout the plate thickness. The present study shows (Figure 1) that the BM material has a heterogeneous microstructure, and $\alpha-\mathrm{RD}$ fiber textures similar to that reported in [30].

In the optical macrograph of the weld cross section (Figure 2), the welded region (i.e. both weld passes) can be distinguished from the BM. However, different zones of the weld within each pass, such as the SAZ and TMAZ, cannot be distinguished at low magnification from the probe dominated area. Differences in the microstructures and grain morphologies of various zones can only be observed at higher magnifications (Figure 3 and Figure 4). The effective tapering of the weld was measured to be $47^{\circ}$ 
which is only slightly greater than the actual $45^{\circ}$ tapering of the probe. A similar observation has been reported for aluminium [25].

In the present study, no temperatures were recorded in the part or at the tool shoulder during the FSW of both weld passes. Therefore, the temperature at the different zones of the weld can only be estimated through the observed microstructure. Overall, the microstructure of the first weld pass is fairly similar to that of the second weld pass where the SZs are mainly bainitic, and the rest of the zones surrounding the SZs including the TMAZ, SAZ and the IZ consist of fine and ultrafine recrystallised ferrite grains (Figure 3 and Figure 4). The observed microstructural differences between the first and the second weld pass are in the range of the SZ and the fraction of bainite (i.e. acicular ferrite) within the SZ. The SZ in the first weld pass is slightly wider than that of the second weld pass, with approximately $5-10 \%$ more bainite in the centre of the SZ, resulting in $\approx 20-30 \mathrm{HV}$ higher hardness (Figure 6), and $\approx 150 \mathrm{MPa}$ higher compressive transverse residual stress (Figure 8a). This can be linked to a slightly faster tool rotational speed during the first weld pass $(200 \mathrm{rpm})$ compared to that of the second weld pass (180 rpm). Previous calculation, based on processing factors such as travel speed, tool rotation speed and torque [28] has shown that $20 \mathrm{rpm}$ increase in tool rotational speed increases the heat input by $10 \%$. Introducing high heat inputs with increased tool rotational rates during FSW and FSP of steels, resulted in higher temperatures and consequently, phase transformation [31-32].

The microhardness map shown in Figure 6a indicates the dominance of the SZs in both weld passes with microhardness values above $\approx 240 \mathrm{HV}$. Due to the overall similarity of both weld passes, the investigations on the microstructure evolution and texture development are focused mainly on the second weld pass. Based on these observations, since the microstructure in the SZs contains a mixture of bainite and ferrite, it is considered that during FSW the temperature of banded ferrite-pearlite microstructure of the BM (Figure 1a) exceeded the $\mathrm{Ac}_{1}$. Due to higher heat input, the weld temperature may be slightly higher during the FSW of the first weld pass; however, the mixed bainitic ferrite and granular ferrite microstructure in both weld passes implies that the temperature does not exceed the $\mathrm{Ac}_{3}$ temperature, thereby allowing full transformation to austenite. The $\mathrm{Ac}_{1}$ and $\mathrm{Ac}_{3}$ temperatures of the grade of steel used in this study, with chemical compositions listed in Error! Reference source not found., have been calculated to be $1070 \pm 297 \mathrm{~K}\left(797 \pm 24{ }^{\circ} \mathrm{C}\right)$ and $1159 \pm 308 \mathrm{~K}\left(886 \pm 35^{\circ} \mathrm{C}\right)$ respectively, considering $293 \mathrm{~K} / \mathrm{s}$ $\left(20^{\circ} \mathrm{C} / \mathrm{s}\right)$ heating rate in the analyses. Changing the heating rate by $283 \mathrm{~K} / \mathrm{s}\left(10^{\circ} \mathrm{C} / \mathrm{s}\right)$ (i.e. slower or faster) in the analyses resulted in less than $288 \mathrm{~K}\left(15^{\circ} \mathrm{C}\right)$ variation from the calculated average values [33].

The minimum temperature at which recrystallisation can occur in austenite based on the weight percentages of the chemical compositions in Error! Reference source not found., is calculated to be $\approx 1173 \mathrm{~K}\left(900{ }^{\circ} \mathrm{C}\right)$. This has been calculated according to a procedure developed for estimating the minimum temperature required for austenite recrystallisation during hot rolling of steels (Equation 1), known as the recrystallisation stop temperature [34].

$$
887+464 C+(6645 N b-664 \sqrt{N b})+(732 V-230 \sqrt{V})+890 T i+363 A l-357 S i
$$

Equation 1

The heating cycle generated by the FSW, transforms the original BM microstructure of the SZs to austenite-ferrite dual phase state at temperatures between $\mathrm{Ac}_{1}-\mathrm{Ac}_{3}$. These mixed phases are then subjected to sever plastic deformation by the FSW. On cooling, the austenite phase undergoes solid state phase transformation to acicular bainitic ferrite under conditions of rapid cooling and high shear strain [35-36]. The bainitic-ferritic microstructure formed in the SZs (Figure 3) varies, depending on the 
temperature distribution from the centre of the SZ toward TMAZ, as the fraction of bainite reduces with an increase in the fraction of granular ferrite (Figure 3). This shows that the temperature in the vicinity of the pin can be significantly lower, possibly below the $\mathrm{Ac}_{1}$, compared to that close to the tool shoulder.

In TMAZ and IZ (Figure 3, Figure 4 and Figure 5) fine and ultrafine equiaxed ferrite have been observed, similarly to the formation of fine grains during single pass FSW of other grades of steels [5, 21, 27, 37 41]. No evidence of bainite has been seen in these zones suggesting that the temperature was below the $\mathrm{Ac}_{1}$ during the FSW. The formation of fine and ultrafine ferrite grains in these zones can be due to the continuous dynamic recrystallisation caused by substantial levels of shear deformation and the heat induced by the FSW process. The continuous dynamic recrystallisation occurs due to the progressive formation of low angle grain boundaries (LAGBs) within the grains subjected to sever plastic deformation, and the eventual conversion of these LAGBs to high angle grain boundaries (HAGBs) upon reaching a critical misorientation angle [42]. Previous studies have reported the formation of ultra-fine ferrite $(<3 \mu \mathrm{m})$ under high levels of shear strains and undercooling, through a single hot rolling pass applied to hypoeutectoid steels [43-44]. Application of very high levels of strain under precise temperature control, lead to the nucleation of intragranular polygonal ferrite on the substructure of austenite during deformation, known as 'dynamic strain-induced transformation' [45-46]. However, in this study, since the TMAZ and the IZ are subjected to shear deformation during FSW at temperatures below $\mathrm{Ac}_{1}$, it is unlikely that the formation of ultrafine ferrite is caused by dynamic strain-induced transformation.

Generally, the welding process in steels, in particular conventional fusion welding, results in the creation of transformed phases such as martensite and bainite in the weld microstructure [47]. The formation of these phases can lead to the deterioration of the mechanical properties of the welded joints due to their brittleness. Despite of exhibiting lower mechanical strength, ferrite is an alternative favourable microstructure due to its high toughness [48]. However, based on the Hall-Pitch relationship, the grain size refinement of the ferrite would results in improved mechanical strengths, including hardness, yield stress, and toughness simultaneously [49]. Therefore, the formation of fine and ultrafine ferrite structure in TMAZ and the IZ of the microalloyed steel are desired to maximise the strengths of the welded joints.

Figure 4 shows the high resolution OIM of the SZs, TMAZ and of the IZ, while the misorientation angle distributions for these microstructures are shown in Figure 9. The high resolution OIM of the single weld pass shows acicular ferrite grain colonies with similar crystallographic orientations (i.e. small misorientations); each can be different variants of the same prior austenite grain (Figure 4). The significant fraction of LAGBs and substructures in the misorientation angle distribution of the SZs is due to transformation induced lattice distortion and the ferrite colonies containing grains with small misorientations (Figure 9). Sub-micron $(\sim 0.8 \mu \mathrm{m})$ equiaxed ferrite grains in the IZ, with the misorientation angle distribution fitting well with the MacKenzie distribution for randomly oriented assembly of grains (Figure 9), suggests that the ferrite grains are recrystallised through continuous dynamic recrystallisation. Note that the microstructure in the transient zone between HAZ and TMAZ has similar misorientation angle distribution to that of the IZ. However, the overlapping process has resulted in significantly finer grain size $(\sim 0.8 \mu \mathrm{m})$ in the IZ compared to that of the TMAZ $(\sim 3-4 \mu \mathrm{m})$ (see Figure 5). Interestingly, Figure 8 shows minimum measured residual stress components in areas with recrystallised ferrite grains (i.e. TMAZ and IZ). In particular the contour plot of the stress component along the ND (Figure 8b) shows the areas with lowest stress values match well with TMAZ of both weld 
passes and the IZ. This indicates that the type II residual stress that arise from strain incompatibilities in the microstructure (i.e. lattice distortions) are minimised following the recrystallisation [50-51].
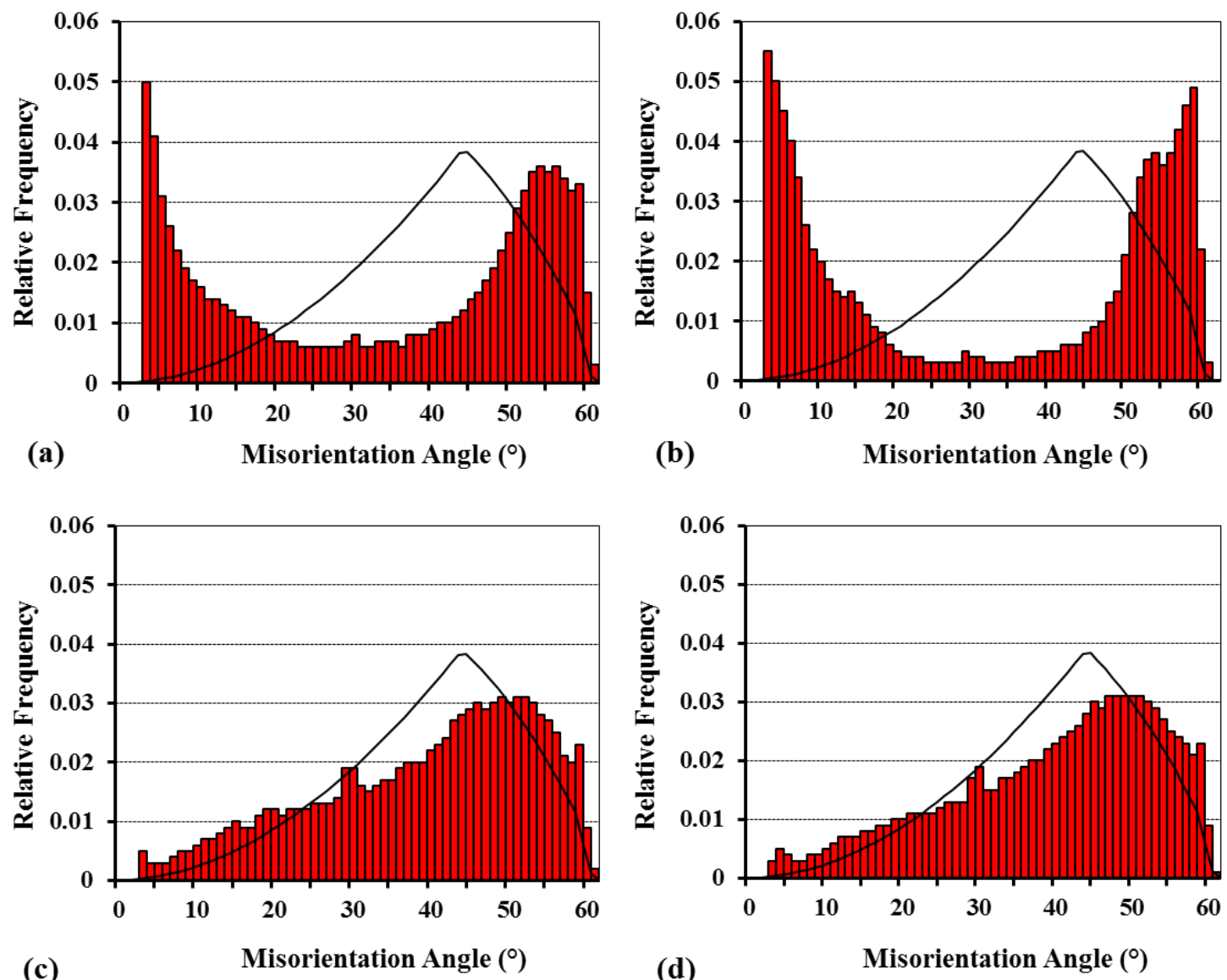

Figure 9: Misorientation angle distributions of (a) the $\mathrm{SZ}$ of the first weld pass, (b) the SZ of the second weld pass, (c) TMAZ and (d) centre of IZ.

\subsection{Texture Development}

Alternating texture and the well-known onion ring structures in FSW have frequently been reported, in which the bands are believed to be of a periodicity equal to tool advance per revolution [52]. The band structure in Figure 7 is not as sharp and distinguishable as those reported for aluminium [25], possibly due to the design of the probe. The formation of bands is attributed to features like threads, flutes and flats in the probe [53-54]. Also, the post FSW phase transformation during cooling might change the appearance of the bands in materials such as steels that undergo austenite $\rightarrow$ ferrite transformation. A previous study on FSW in titanium, that undergoes a similar $\alpha \rightarrow \beta$ phase transformation, has reported the absence of bands and onion ring structures in TMAZ [55].

As previously reported for aluminium alloys and pure iron [6, 52-53], the entire SZ and TMAZ are dominated by off-axis shear textures. A clear systematic rotation of the texture can be observed across the SZ, from far RS to the far AS (Figure 7 a). Similar observations have been reported for aluminium [25] and a titanium alloy that like the material investigated in this study, undergoes phase transformation [55]. This implies that the texture within TMAZ and SZ are equivalent, and can be related to each other by two rotation angles; a rotation angle $(\alpha)$ about the ND and a constant tilt angle $(\beta)$ about a direction perpendicular to the ND. Based on a methodology developed for aluminium [25], the systematic rotation of the texture about the ND as a function of distance, $x$, from the centre of the weld in the TD can be 
determined by Equation 2. In Equation 2, $x_{0}$ is the radius of the weld, including both SZ and TMAZ, at the point of interest. This relationship shows that the material adjacent to the probe is sheared in the direction of probe tangent, such that the shear surface in the post weld microstructure has a semicircular shape, formed by shear around the trailing edge of the probe.

$$
\alpha=\sin ^{-1}\left(\frac{x}{x_{0}}\right)
$$

Equation 2

The EBSD data points obtained from the weld cross-section (Figure 2), in which the orientations are defined as Euler angles with respect to the specimen axes (WD, TD, ND), are transformed to the local shear reference frame $(\theta, Z, r)$, using an in-house developed software in MATLAB, based on an approach demonstrated for aluminium [25]. This includes the multiplication of each point's orientation matrix, $G$, by $R_{\alpha}$ to account for rotation angle of $\alpha$ around $\mathrm{ND}$, followed by multiplication by $R_{\beta}$ to rotates the new orientation matrix by a constant angle of $\beta$ around TD, according to Equation 3. In these analyses, $\alpha$ has been calculated from Equation 2 considering $x_{0}=6900 \mu \mathrm{m}$ for the RS and $x_{0}=6400 \mu \mathrm{m}$ for the AS, and applied to the EBSD maps acquired across TMAZ and SZ of the second weld pass. The slightly smaller radius of the weld on the AS can be due to the forward motion of the tool, that has an opposite effect on the radius on the RS of the weld due to opposing directions of motion [25]. The measured slope of weld, $\beta=47^{\circ}$, in the probe dominated area from the vertical, is used for the calculation of rotation around TD. In this analysis, $\alpha$ has been considered negative for a clockwise rotation and positive for an anticlockwise. The results of these rotations, which describe the orientation of each data point with regard to the local shear reference frame, are shown in Figure 10. These maps are taken from the centre of TMAZ on RS side to the centre of TMAZ on the AS side. The rotated maps show that the data is dominated by $<101>$ crystal directions parallel to the $r$ direction of the local shear reference frame, with more dominance of $\langle 001\rangle$ and $<111>$ in TMAZ. A slight rotation of the shear reference fame can be seen towards both ends of the SZ, and in the TMAZ that can be due to the tool's vibration.

$G_{r}=G R_{\alpha} R_{\beta}$

$R_{\alpha}=\left(\begin{array}{ccc}\cos \alpha & \sin \alpha & 0 \\ -\sin \alpha & \cos \alpha & 0 \\ 0 & 0 & 1\end{array}\right), \quad R_{\beta}=\left(\begin{array}{ccc}1 & 0 & 0 \\ 0 & \cos \beta & \sin \beta \\ 0 & -\sin \beta & \cos \beta\end{array}\right)$ 


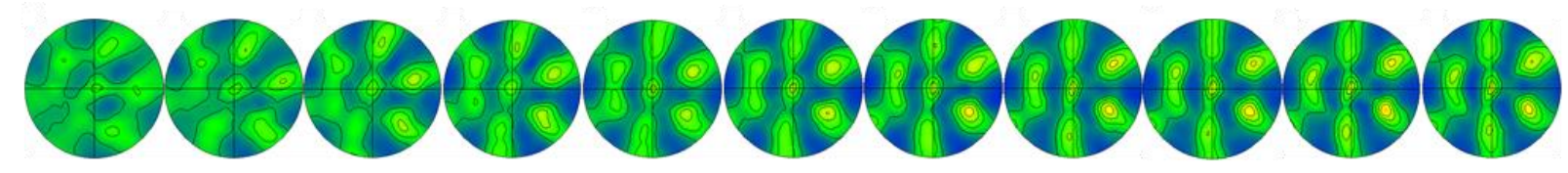

TAMZ

SZ

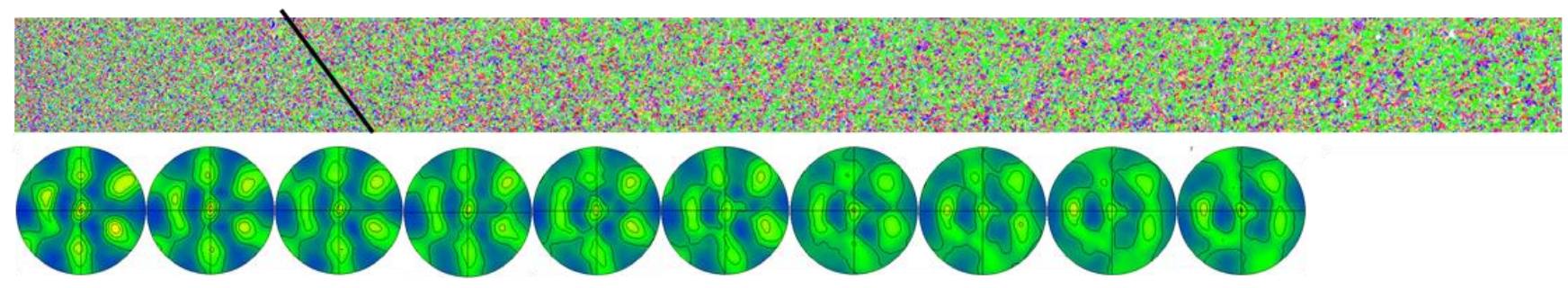

SZ

TMAZ
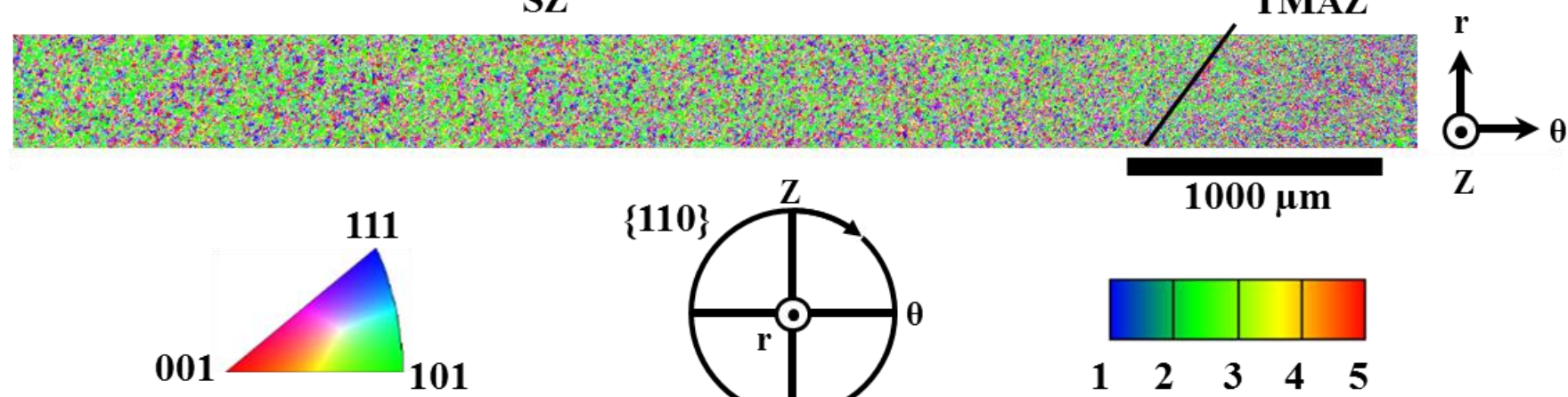

$1000 \mu \mathrm{m}$

Z
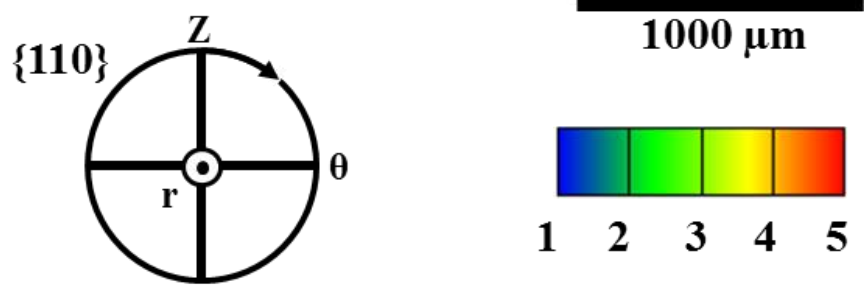

Figure 10: EBSD IPF colouring across TMAZ and SZ of the second weld pass (Figure 7 a) after rotation correction with respect to the local shear reference frame (i.e. ' $r$ ' direction), along with their resultant (110) pole figures. The pole figures are presented with $Z$ on top, shear direction $(\theta)$ on right and $r$ in the centre.

The rotated data shown in Figure 10 allows further analyses of texture components relative to the shear reference frame at a point of interest across TMAZ and SZ. Shear textures are conventionally defined in terms of crystallographic plane $\{h k l\}$ and direction $\langle u v w\rangle$ aligned parallel to the shear plane normal (Z) and shear direction $(\theta)$, respectively. This, in fcc materials, is the alignment of the $\{111\}$ slip planes with the $\mathrm{Z}$ and the $\langle 110\rangle$ slip direction with $\theta$; and in bcc materials the ideal orientations formed by simple shear deformation are along two partial fibres of $\{h k l\}\langle 111\rangle$ and $\{110\}\langle u v w\rangle$. These contain different ideal shear components that are summarised in Table 2 [56]. For the microalloyed steel investigated in this study, the shear deformations are taking place at various temperatures, depending on the position within the weld. Based on the microstructural observations discussed earlier, the temperature in the TMAZ and IZ is close to or below the $\mathrm{Ac}_{1}$ temperature, where the microstructure is still ferritic with $b c c$ crystal structure, and that of the $\mathrm{SZs}$ are at temperatures between $\mathrm{Ac}_{1}-\mathrm{Ac}_{3}$, where the microstructure is partially ferritic, and partially austenitic with $f c c$ crystal structure. Therefore, the deformation textures of the TMAZ and IZ with respect to the shear reference frame are expected to be similar to the ideal shear deformation in $b c c$ metal, and that of the SZ should contain both ideal shear deformation components of $b c c$ metal (i.e. ferrite) and $f c c$ metal (i.e. austenite), considering that the texture can be inherited during the austenite to ferrite transformation [57-59]. There are well established crystallographic orientation relationships (OR) such as Kurdjumov-Sachs (KS) and Nishiyama-Wasserman (NW) that relate ferrite to austenite, following transformation on cooling. KS and NW crystallographic orientation relationships describe the symmetry equivalent of planes and directions in austenite $(\gamma)$ and ferrite $(\alpha)$ phases such that $\{111\} \gamma / /\{110\} \alpha-<110>\gamma / /<111>\alpha[60]$, and $\{111\} \gamma / /\{110\} \alpha-<112>\gamma / /<110>\alpha$, respectively; although, it is recognised that an exact OR, even in the case of near equilibrium iron, might not be achieved [61-62]. The experimentally measured textures of the TMAZ, IZ and the SZ, following the 
rotation corrections from the sample reference frame to the shear reference frame, are compared with ideal shear deformations of $b c c$ and $f c c$ metals, to understand the deformation mechanisms and microstructure evolution in these areas.

Following the transformation from the sample reference frame (WD, TD, ND) to the local shear reference frame $(\theta, Z, r)$, the rotated polefigures across TMAZ and SZ are essentially the same, implying that the deformation textures are due to shear resulting from the final deformation in the material on the trailing side of the probe $[25,63]$. Figure $11 \mathrm{a}$, shows the $B$ and $\bar{B}$ shear texture components for $\{111\}$ crystallographic planes of fcc metal (see Table 2) superimposed on the $\{110\}$ polefigures of the centreline of the SZ with respect to the local shear reference frame. It can be seen that the poles match reasonably well with the projection of the $B$ and $\bar{B}$ ideal shear texture components of fcc metals (Figure 11a). This implies that during FSW, when temperature is between $\mathrm{Ac}_{1}-\mathrm{Ac}_{3}$, the microstructure becomes austenitic/ferritic and both phases undergo shear deformation simultaneously, where $B$ and $\bar{B}$ are the dominant shear texture components in austenite. The deformed austenite then transforms to ferrite on cooling, and based on the KS - OR, the $\{110\}$ planes of ferrite are parallel to $\{111\}$ of austenite (i.e. $\{111\} \gamma / /\{110\} \alpha-<110>\gamma / /<111>\alpha)$. Previous investigations on API X80 pipeline steel has also shown that $B$ and $\bar{B}$ are the most dominant shear texture components in prior austenite during FSW [64]. However, there are slight rotations of the measured $\{110\}$ poles from the ideal shear components for $\{111\}$ planes of fcc (Figure 11a). Although, the rotations of the ideal orientations around the shear axis in both fcc and bcc metals have been reported previously [57-59], since the shear deformation occured in austenitic - ferritic regime, the poles are slightly biased toward the ideal shear texture components for $\{110\}$ crystallographic planes of bcc metal.

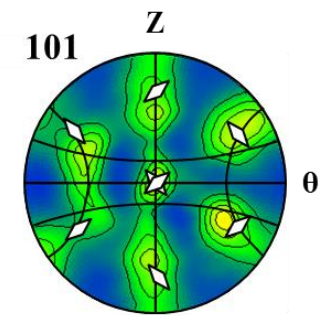

(a)
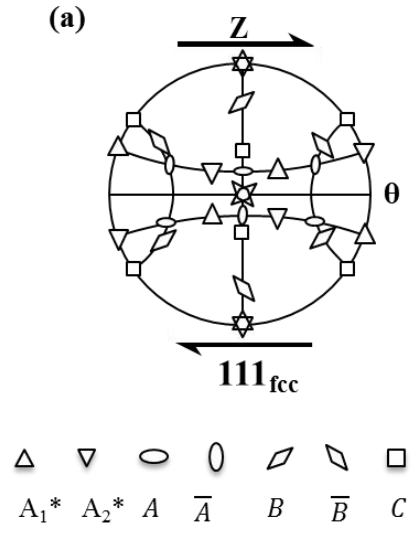

(d)

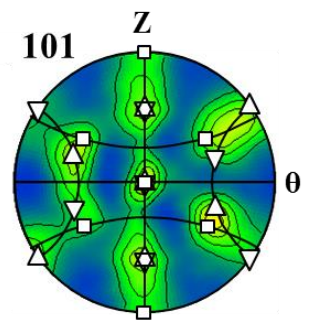

(b)

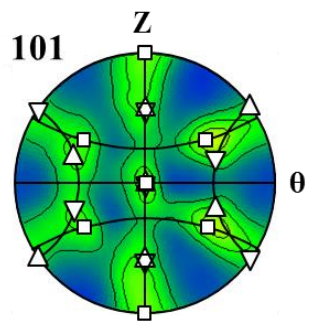

(c)
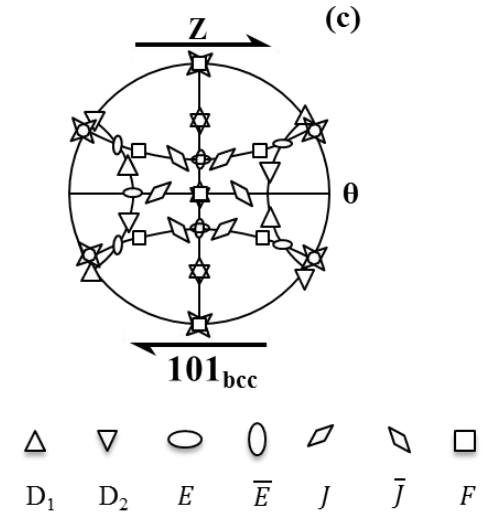

(e)

Figure 11: $\{110\}$ polefigure displaying the texture in terms of the local shear reference frame (i.e. shear direction $(\theta)$, and shear plane normal $(Z)$ ) of (a) the centreline of the $S Z$, with $B$ and $\bar{B}$ components of the ideal shear deformation components for fcc metals superimposed, (b) and (c) the centreline of the SZ the centre of the IZ respectively, with $D_{1}, D_{2}$ and $C$ components of the ideal shear deformation components for bcc metals superimposed. (d) and (e) are the ideal shear deformation components for fcc and bcc metals, respectively, for which the data are taken from Ref [56]. 
Table 2: Ideal crystallographic orientations in simple shear deformation of bcc and fcc materials [56]

\begin{tabular}{|c|c|c|c|c|c|}
\hline \multirow{2}{*}{$\begin{array}{c}\text { Crystal } \\
\text { Structure } \\
\end{array}$} & \multirow{2}{*}{$\begin{array}{c}\text { Shear } \\
\text { Component }\end{array}$} & \multirow{2}{*}{$h k l$}$\langle u v w\rangle$ & \multicolumn{3}{|c|}{ Euler Angles $\left(^{\circ}\right)$} \\
\hline & & & $\varphi_{1}$ & $\varphi$ & $\varphi_{2}$ \\
\hline \multirow{10}{*}{ fcc } & \multirow{2}{*}{$A_{l}{ }^{*}$} & $\multirow{2}{*}{111}<\overline{1} 1 \overline{2}>$ & $35.3 / 215.3$ & 45 & 0 \\
\hline & & & $125.3 / 305.3$ & 90 & 45 \\
\hline & \multirow{2}{*}{$A_{2}{ }^{*}$} & $\multirow{2}{*}{111}<11 \overline{2}>$ & $144.7 / 324.7$ & 45 & 0 \\
\hline & & & $54.7 / 234.7$ & 90 & 45 \\
\hline & $A$ & $\{1 \overline{1} 1\}<110>$ & 0 & 35.3 & 45 \\
\hline & $\bar{A}$ & $\{1 \overline{1} 1\}<\overline{1} \overline{1} 0>$ & 180 & 35.3 & 45 \\
\hline & $B$ & $\{1 \overline{1} 2\}<110>$ & $0 / 120 / 240$ & 54.7 & 45 \\
\hline & $\bar{B}$ & $\{\overline{1} 1 \overline{2}\}<\overline{1} \overline{1} 0>$ & $60 / 180 / 300$ & 54.7 & 45 \\
\hline & \multirow{2}{*}{$C$} & $\multirow{2}{*}{001}<110>$ & $90 / 270$ & 45 & 0 \\
\hline & & & $0 / 180$ & 90 & 45 \\
\hline \multirow{10}{*}{ bcc } & \multirow{2}{*}{$D_{1}$} & $\multirow{2}{*}{\overline{1} \overline{1} 2}<111>$ & $54.7 / 234.7$ & 45 & 0 \\
\hline & & & $144.7 / 324.7$ & 90 & 45 \\
\hline & \multirow{2}{*}{$D_{2}$} & $\multirow{2}{*}{11 \overline{2}}<111>$ & $125.3 / 305.3$ & 45 & 0 \\
\hline & & & $35.3 / 215.3$ & 90 & 45 \\
\hline & $E$ & $\{110\}<1 \overline{1} 1>$ & 90 & 35.3 & 45 \\
\hline & $\bar{E}$ & $\{\overline{1} \overline{1} 0\}<1 \overline{1} 1>$ & 270 & 35.3 & 45 \\
\hline & $J$ & $\{110\}<1 \overline{1} 2>$ & $90 / 210 / 330$ & 54.7 & 45 \\
\hline & $\bar{J}$ & $\{\overline{1} \overline{1} 0\}<\overline{1} 1 \overline{2}>$ & $30 / 150 / 270$ & 54.7 & 45 \\
\hline & \multirow{2}{*}{$F$} & $\multirow{2}{*}{110}<001>$ & $0 / 180$ & 45 & 0 \\
\hline & & & $90 / 270$ & 90 & 45 \\
\hline
\end{tabular}

Figure $11 \mathrm{~b}$ and c show the $D_{1}, D_{2}$ and $F$ shear texture components for $\{110\}$ crystallographic planes of bcc metals superimposed on the $\{110\}$ polefigures of the centreline of the SZ and that of the centre of the IZ, respectively. The measured $\{110\}$ poles match the projection of the $D_{1}, D_{2}$ and $F$ ideal shear texture components of bcc metal, indicating that the deformation occurred below the $\mathrm{Ac}_{3}$ temperature. A welldefined $D$ shear texture component has been observed in friction stir processed pure iron where the postweld microstructure was reported to be mainly polygonal ferrite [21]. In this study, the observed microstructures in the SZ of both weld passes are primarily acicular ferrite and that of the IZ is polygonal ferrite [18], while the resultant texture in both zones are identical (Figure 11b and c). Comparison between these observations and that reported for pure iron [21] imply that FSW results in well-defined D shear texture components in bcc ferrite, disregarding the cooling rate and chemical composition. The reasonably good match between the polefigures of the IZ with the ideal shear texture components of bcc metals (Figure 11c) indicates that in the IZ material undergoes shear deformations at temperatures below $A_{1}$, with dominant $D_{1}$ and $D_{2}$ shear texture components. These observations suggest that the texture across the whole weld is a shear texture with respect to the shear reference frame, (i.e. rotation about the ND as a function of distance from the centre of stir zone $(\alpha)$ and a constant tilt angle $\left(\beta=47^{\circ}\right)$ about TD) with $D_{1}, D_{2}$ and $F$ components dominant. This is confirmed in Figure 12 in which the $D_{1}$ (red), $D_{2}$ (blue) and $F$ (yellow) components with a $25^{\circ}$ spread are highlighted. 


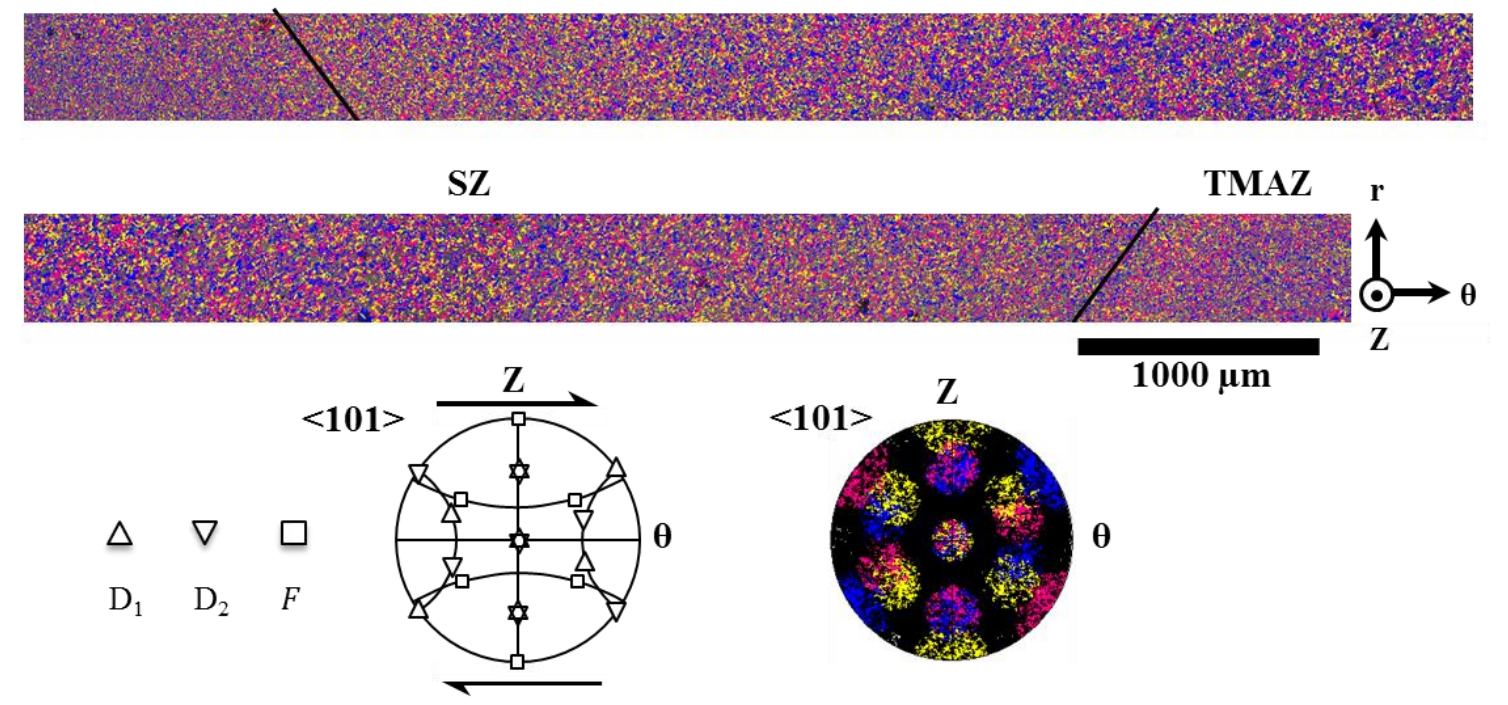

Figure 12: Texture components map after rotation from sample reference frame (WD, TD, ND) to the local shear reference frame $(\theta, Z, r)$ with $D_{1}$ (Red), $D_{2}$ (Blue) and $F$ (Yellow). Polefigures show the locations of the dominant ideal shear texture components.

Figure 7 shows that one of the $\{111\}$ poles tends to have a significantly higher density when the pole is closest to TD. This is strongest in the middle of TMAZ, within a distance of $1.2 \mathrm{~mm}$ to $3 \mathrm{~mm}$ from the edge of the weld (i.e. SAZ), as is apparent in Figure 7. This is an evidence of significant variant selection during austenite $\rightarrow$ ferrite phase transformation. Previous study on FSW in titanium, that undergoes a similar $\alpha \rightarrow \beta$ phase transformation, reported [55] comparable observations in which the variant selection was caused by preferential growth of certain variants independent of the microstructure, texture, or grain morphology of the $\beta$ phase. It was suggested that the observed variant selection was caused by a factor that remains the same in the workpiece axes, such as the directionality of the heat transfer and the thermally induced stresses in the weld, due to constrained thermal contraction during cooling [55].

\section{Conclusion}

In this study, detailed analyses of the microstructure and crystallographic texture in a double-sided friction stir welded microalloyed steel type EH46 were carried. The major observations of this work are concluded as follows:

- The double sided friction stir processing resulted in the formation of ultra-fine equiaxed ferrite with submicron $(<1 \mu \mathrm{m})$ grain size in the IZ, and 3-4 $\mu \mathrm{m}$ grain size in the SAZ and in regions of the TMAZ, in the vicinity of HAZ. The observed refinement can be due to continuous dynamic recrystallisation of ferrite under large shear strains through FSW and severe undercooling.

- It is suggested that the peak temperatures achieved in the SZ during FSW were between $\mathrm{Ac}_{1}-\mathrm{Ac}_{3}$ resulting in a mixed microstructure of polygonal ferrite and predominantly acicular ferrite, due to the austenite-ferrite transformation on cooling.

- The deformation in the SZs occurred at temperatures between $\mathrm{Ac}_{1}-\mathrm{Ac}_{2}$ in the presence of both austenite and ferrite phases. The deformation in austenite is believed to be a simple shear dominated by the $\mathrm{B}\{1 \overline{1} 2\}<110>$ and $\bar{B}\{\overline{1} 1 \overline{2}\}<\overline{1} \overline{1} 0>$ simple shear texture components, as based on KS crystallographic orientation relationship, $\{111\} \gamma / /\{110\} \alpha-<110>\gamma / /<111>\alpha$, a 
good agreement is observed between the measured $\{110\}$ texture and the ideal shear components for $\{111\}$ planes of fcc metal.

- All deformation in TMAZ and the IZ occurred at temperatures below $\mathrm{Ac}_{1}$ where the microstructure was fully ferritic. The deformation in ferrite in all zones, including SZ, TMAZ and the IZ, is shear dominated by $D_{1}\{\overline{1} \overline{1} 2\}<111>$ and $D_{2}\{11 \overline{2}\}<111>$ simple shear texture components.

- A relatively strong variant selection was seen to occur in the SZ during austenite to ferrite phase transformation, which is biased toward a fixed axis of the welded materials and not the local shear reference frame.

\section{Acknowledgements}

The authors would like to acknowledge the support provided by the Advanced Forming Research Centre (AFRC), University of Strathclyde, which receives partial financial support from the UK's High Value Manufacturing CATAPULT. Dr N.A.McPherson, formerly of BAE Systems Marine, Govan, Glasgow, is thanked for providing the FSW specimens.

\section{References}

1. W. M. Thomas, E. D. Nicholas, J. C. Needham, M. G. Murch, P. Temple-Smith, C. J. Dawes, International Patent application no. PCT/GB92/02203 and GB Patent application No. 9125978.8 and US Patent application no. 5,460,317, (1991).

2. W. M. Thomas, C. J. Dawes, Weld 1996, vol. 75, pp. 41 - 45.

3. G. Cam, Int. Mater. Rev. 2011, vol. 56, pp. 1 - 48.

4. J. M. Root, D. P. Field, T. W. Nelson, Metall. Mater. Trans. A 2009, vol. 40, pp. 2109-2014.

5. $\quad$ Y. S. Sato, T. W. Nelson, C. J. Sterling, Acta Mater. 2005, vol. 53, pp. 637 - 645.

6. S. Mironov, Y. S. Sato, H. Kokawa, H. Inoue, S.Tsuge Acta Mater. 2011, vol. 59, pp. 5472-5481.

7. T. J. Lienert, W. L. Stellwag, B. B. Grimmett, R. W. Warke, Supplement Weld. J 2003, vol. 82, pp. 1s - 9s.

8. $\quad$ M. Gosh, K. Kumar, R. S. Mishra, Scripta Mater. 2010, vol. 63, pp. 851 - 854.

9. J. Young, D. P. Field, T. W. Nelson, Metall. Mater. Trans. A 2013, vol. 44, pp. 3167 - 3172.

10. M. Jafarzadegan, A. Abdollah-zadeh, A. H. Feng, T. Saeid, J. Shen, H. Assadi, J. Mater. Sci. Technol. 2013, vol. 29, pp. 367 - 372.

11. S. J. Barnes, A. Steuwer, S. Mahawish, R. Johnson, P. J. Withers, Mater. Sci. Eng., A 2008, vol. 492, pp. 35 - 44.

12. P. J. Konol, J. A. Mathers, R. Johnson, J. R. Pickens, J. Ship Prod. 2003, vol. 19, pp. 159 - 164.

13. N. A. McPherson, A. M. Galloway, S. R. Cater, M. M. Osman, In 19th Int.Conf. Trends in Welding Research, (2013), pp 284 - 290.

14. G. P. Mercier, M. Reik, Concurrent Technologies Corporation2000.

15. P. A. Manohar, M. Ferry, T. Chandra, ISIJ Int. 1998, vol. 38, pp. 913 - 924.

16. S. F. Medina, A. Quispe, M. Gomez, Mater. Sci. Forum 2012, vol. 706, pp. 2176-2180.

17. S. Vervynckt, K. Verbeken, B. Lopez, J. J. Jonas, Int. Mater. Rev. 2012, vol. 57, pp. 187 - 207.

18. T. N. Baker, N. A. McPherson, Mater. Sci. Technol. 2016, p. in press.

19. P. L. Threadgill, Sci. Technol. Weld. Joining 2007, vol. 12, pp. 357 - 360.

20. A. Toumpis, A. Galloway, S. Cater, N. McPherson, Mater. Des. 2014, vol. 62, pp. 64-75.

21. S. Mironov, Y. S. Sato, H. Kokawa, Acta Mater. 2008, vol. 56, pp. 2602-2614.

22. H. H. Cho, H. N. Han, S. T. Hong, J. H. Park, Y. J. Kwon, S. H. Kim, R. J. Steel, Mater. Sci. Eng., A 2011, vol. 528, pp. 2889-2894.

23. D. P. Field, T. W. Nelson, Y. Hovanski, K. V. Jata, Metall. Mater. Trans. A 2001, vol. 2869-2877. 
24. Y. S. Sato, H. Kokawa, K. Ikeda, M. Enomoto, S. Jogan, T. Hashimoto, Metall. Mater. Trans. A Microtexture in the friction-stir weld of an aluminum alloy, vol. 32, pp. 941-948.

25. M. M. Z. Ahmed, B. P. Wynne, W. M. Rainforth, P. L. Threadgill, Scripta Mater. 2008, vol. 59, pp. $507-510$.

26. B. D. Nelson, (Brigham Young University: 2010).

27. H. H. Cho, S. H. Kang, S. H. Kim, K. H. Oh, H. J. Kim, W. S. Chang, H. N. Han, Mater. Des. 2012, vol. 34, pp. 258-267.

28. P. Baillie, S. W. Campbell, A. M. Galloway, S. R. Cater, N. A. McPherson, International Journal of Chemical, Nuclear, Metallurgical and Materials Engineering 2014, vol. 8, pp. 651 - 655.

29. M. E. Fitzpatrick, A. T. Fry, P. Holdway, F. A. Kandil, J. Shackleton, L. Suominen, NPL Measurement Good Practice Guide No. 52, 2005.

30. D. Raabe, K. Lüucke, Mater. Sci. Technol. 1993, vol. 9, p. 302.

31. M. Ghosh, K. Kumar, R. S. Mishra, Mater. Sci. Eng., A 2011, vol. 528, pp. 8111-8119.

32. M. Matsushita, Y. Kitani, R. Ikeda, M. Ono, H. Fuji, Y. D. Chung, Sci. Technol. Weld. Joining 2011, vol. 16, pp. 181-187.

33. L. Gavard, H. K. D. H. Bhadeshia, D. J. C. Mackay, S. Suzuki, Mater. Sci. Technol. 1996, vol. 12, pp. 453-463.

34. F. Borrato, R. Barbosa, S. Yue, J. J. Jonas, In Thermec, (1988), pp 383 - 390.

35. J. R. Yang, H. K. D. H. Bhadeshia, Adv Weld Technol Sci 1987, vol. 1, pp. 187-191.

36. R. A. Farrar, P. L. Harrison, J Mater Sci. 1987, vol. 22, pp. 3812-3820.

37. A. P. Reynolds, W. Tang, T. Gnaupel-Herold, H. Prask, Scripta Mater. 2003, vol. 48, pp. 12891294.

38. H. K. D. H. Bhadeshia, T. Debroy, Sci. Technol. Weld. Joining 2009, vol. 14, pp. 193-196.

39. U. F. H. R. Suhuddin, S. Mironov, Y. S. Sato, H. Kokawa, C. W. Lee, Acta Mater. 2009, vol. 57, pp. 5406-5418.

40. Y. S. Sato, T. W. Nelson, C. J. Sterling, R. J. Steel, C. O. Pettersson, Mater. Sci. Eng., A 2005, vol. 397, pp. 376-384.

41. Y. S. Sato, H. Yamanoi, H. Kokawa, T. Furuhara, Scripta Mater. 2007, vol. 57, pp. 557-60.

42. S. Gourdet, F. Montheillet, Acta Mater., vol. 51, pp. 2685-2699.

43. X. J. Zhang, P. D. Hodgson, P. F. Thomson, J. Mater. Process. Technol. 1996, vol. 60, pp. 615 619.

44. P. D. Hodgson, M. R. Hickson, R. K. Gibbs, Mater. Sci. Forum 1998, vol. 284-286, pp. 63-72.

45. R. Priestner, E. de los Rios, Metals Technology 1980, vol. 7, pp. 309 - 316.

46. P. J. Hurley, P.D. Hodgson, Mater. Sci. Eng., A 2001, vol. 302, pp. 206 - 214.

47. L. Y. Wei, T. W. Nelson, Mater. Sci. Eng., A 2012, vol. 556, pp. 51 - 59.

48. D. Zhang, H. Terasaki, Y. Komizo, Acta Mater. 2010, vol. 58, pp. $1369-1378$.

49. F. R. Xiao, B. Liao, Y. Y. Shan, G. Y. Qiao, Y. Zhong, C. L. Zhang, K. Yang, Mater. Sci. Eng., A 2006, vol. 431, pp. 41-52.

50. P. J. Withers, H. K. Bhadeshia, Mater. Sci. Technol. 2001, vol. 17, pp. 366 - 375.

51. P. J. Withers, H. K. D. H. Bhadeshia, Mater. Sci. Technol. 2001, vol. 17, pp. 355 - 365.

52. R. W. Fonda, J. F. Bingert, K. J. Colligan, Scripta Mater. 2004, vol. 51, pp. 243 - 248.

53. P. B. Prangnell, C. P. Heason, Acta Mater. 2005, vol. 53, pp. 3179 - 3192.

54. R. Nanadan, T. DebRoy, H. K. D. H. Bhadeshia, Prog. Mater Sci. 2008, vol. 53, pp. 980 - 1023.

55. P. S. Davies, B. P. Wynne, W. M. Rainforth, M. J. Thomas, P. L. Threadgill, Metall. Mater. Trans. A 2011, vol. 42, pp. 2278 - 2289.

56. R. W. Fonda, K. E. Knipling, Sci. Technol. Weld. Joining 2011, vol. 16, pp. 288 - 294.

57. F. Montheillet, M. Cohen, J. J. Jonas, Acta Metall. 1984, vol. 32, pp. 2077 - 2089.

58. J. Baczynski, J. J. Jonas, Acta Mater. 1996, vol. 44, pp. 4273 - 4288.

59. S. Li, I. J. Beyerleinb, M. Bourkea, Mater. Sci. Eng., A 2005, vol. 394, pp. 66 - 77.

60. G. Kurdjumove, G. Z. Sachs, Physics 1930, vol. 64, pp. 325 - 343.

61. Y. He, S. Godet, J. J. Jonas, Acta Mater. 2005, vol. 53, pp. 1179-1190.

62. Y. He, S. Godet, P. J. Jacques, J. J. Jonas, Acta Mater. 2006, vol. 54, pp. 1323-1334. 
63. K. E. Knipling, R. W. Fonda, Scripta Mater. 2009, vol. 60, pp. 1097 - 1100.

64. M. Abbasi, T. W. Nelson, C. D. Sorensen, Metall. Mater. Trans. A 2012, vol. 43, pp. 4940 - 4946. 